\title{
Theoretical Study on Pentiptycene Molecular Brake: Photoinduced Isomerization and Photoinduced Electron Transfer
}

\section{Hailong Wang}

Xiangtan University

Qiuping Guan

Xiangtan University

Xueye Wang ( $\nabla$ wxueye@xtu.edu.cn )

Xiangtan University https://orcid.org/0000-0001-5578-6504

\section{Research Article}

Keywords: Density functional theory, Electron transfer, Molecular brake, Pentiptycene, Photoisomerization

Posted Date: May 18th, 2021

DOI: https://doi.org/10.21203/rs.3.rs-507449/v1

License: (c) (i) This work is licensed under a Creative Commons Attribution 4.0 International License.

Read Full License 


\title{
Theoretical Study on Pentiptycene Molecular Brake: Photoinduced Isomerization and Photoinduced Electron Transfer
}

\author{
Hailong Wang, Qiuping Guan, Xueye Wang * \\ Key Laboratory for Green Organic Synthesis and Application of Hunan Province, Key \\ Laboratory of Environmentally Friendly Chemistry and Applications of Ministry of Education, \\ College of Chemistry, Xiangtan University, Xiangtan, Hunan 411105, PR China
}

\begin{abstract}
The isomerization of the double bond plays an important role in the braking and de-braking of the light-driven molecular brake. Therefore, the Pp-type light-controlled molecular brake system containing the $\mathrm{C}=\mathrm{C}$ double bond was theoretically studied. Combining the 6-31G(d) basis set, the $\omega \mathrm{B} 97 \mathrm{XD}$ functional with dispersion correction was applied to implement the (E)-configuration and (Z)-configuration initial optimization. Next, using the 6-311G(d,p) basis set, the relaxed potential energy surface scans of the rotation angle were operated, and then the optimization calculations of the transition states at the extremum high points. Analyzing the stagnation points and the rotational transition state on the MEPs, the rotation mechanism and basic energy parameters of the molecular brake were obtained. Then the DFT computations at ground states and the TD-DFT computations of vertical excitation energy was put into practice at the accuracy of the def-TZVP basis set for the two configurations, and using the natural transition orbital (NTOs) analyses combining the excitation energies and absorption spectrums of the molecules, the electronic transition characteristics and electron transfer properties of light-driven molecular brake were studied. Afterwards, in order to investigate the photo-induced isomerization reaction, the $\mathrm{C}=\mathrm{C}$ double bond was scanned on the relaxed potential energy surface, and the intermediates of the isomerization reaction was searched and analyzed, thus, the braking mechanism of the light-driven molecular brake was proposed.
\end{abstract}

KEY WORDS: Density functional theory; Electron transfer; Molecular brake; Pentiptycene; Photoisomerization

* Corresponding author. Tel: +86 0731 58292206; Fax: +86 0731 58292251; E-mail: wxueye@xtu.edu.cn 


\section{Declarations}

Funding (information that explains whether and by whom the research was supported)

There is no supported Funding

Conflicts of interest/Competing interests (include appropriate disclosures)

There are no competing conflicts

Availability of data and material (data transparency)

The data and material of the current study are available from the corresponding author

Code availability (software application or custom code)

Not applicable

Authors' contributions (optional: please review the submission guidelines from the journal whether statements are mandatory)

Hailong Wang: Calculation, discussion and writing

Qiuping Guan: Discussion

Xueye Wang: Theoretical guidance and discussion

Ethics approval (include appropriate approvals or waivers)

Approvals

Consent to participate (include appropriate statements)

We declared our agreement

Consent for publication (include appropriate statements)

We declared our agreement 


\section{INTRODUCTION}

The artificial molecular machines is uniquely positioned to play asignificant role in nanoscience and technology, it has been becoming a new and rapidly emerging field of chemistry and physics.In fact, the level of control the motions of molecular brakes ${ }^{[1-28]}$ is still and will be in the stage of development for a quite long time. The light-driven molecular brake is a typical rotary motions controller which could be defined as a molecular or supramolecular system that effectively controls intra-molecular or inter-fragment rotational motion via photochemical reactions such as photoisomerization, photooxidation and so on ${ }^{[17,29]}$. Recent years, the concept of green chemistry is gradually attracting attention since the environmental protection issues are valued by all walks of life, especially scientific research. Light is considered to be one of the cleanest, fastest input and most accessible energy sources, so it is favored deeply by scientific researchers.

Herein the molecular brake system containing a $\mathrm{C}=\mathrm{C}$ double bond and a pentiptycenyl $(\mathrm{Pp})$ group was selected as the research object (Scheme 1). Since $\mathrm{C}=\mathrm{C}$ double bonds can be stimulated by light to propagate isomerization on the excited state potential energy surface, the molecular configuration can be controllably transformed from $(E)$ - to $(Z)$ - or $(Z)$ - to $(E)$ - by irradiation with light of different frequencies.That is, the styryl group is the brake $\operatorname{pad}^{[15-18]}$. Recognized as a four-bladed model, the Ppsegmentwasthe rotator with excellent performance of the molecular brake. On the one hand, Pp has been well studied as molecular gear and brake, in which the phenyl moieties in the center may have a great promotion on the electron delocalization, causing the enable of photoinduced configuration transformation to be realized.On the other hand, $\mathrm{Pp}$ is not a complete space quadruple structure, which is facilitating to add some other modification groups between the two more distant blade on the same side (blue labeled in Scheme 1), so as not to make the atom density too large and unstable. It can freely and fastly rotate around the single bond (C2-C39) due to the low rotating energy barrier when the $(E)$-type configuration $((E)-1)$ is adopted. While the (Z)-type formed, a pad snaps into the middle of the two blades, leading to resistance increase, thence the energy barrier is higher and the rotational motion slows down. As a common sense, almost all molecules that are sensitive to light stimulation are configured with great conjugation, which leads to the very strong electron delocalization. Therefore, the molecule is excited by light, triggering the electron transitions, further causing the occurrence of photoinduced electron transfer (PET) process.In view of this, to investigate the electronic properties in the process of photochemical reactions, the dimethylamino group and phenylstilbene chromophorewere introduced as electron donors and acceptors, respectively.

The thermodynamics properties of ground state and excited state, spectral properties, molecular dynamics properties,braking mechanism and the electron transfer were studied by computational method using the Kohn-Sham density functional theory (KS-DFT, abbreviated as DFT). The mechanism of the photoinduced isomerization reaction has been pointed out according 
to the team of Yang ${ }^{[17]}$, and there are some theoretical supportingof the previous standpoints. It is a light-induced angular torsion reaction that occurs on the potential energy surface of the singlet excited state (S1) undergoing $\mathrm{p}$ and $\mathrm{p}^{*}$ states. Therefore, all calculations regarding excited states are based on singlet states.

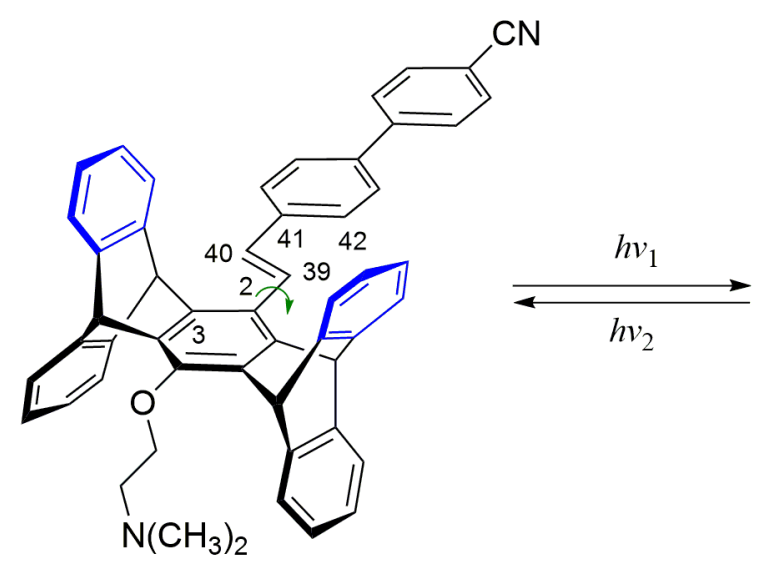

$(E)-\mathbf{1}$

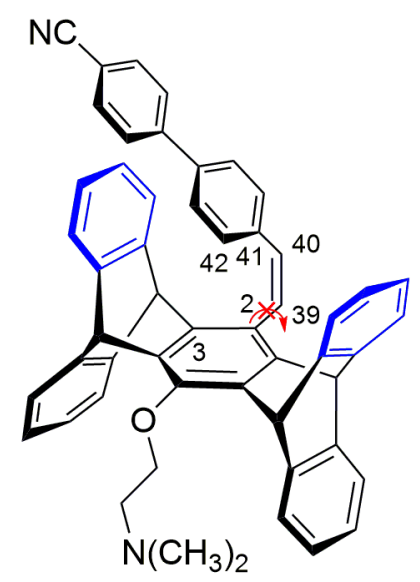

$(Z)-1$

OFF

ON

Scheme 1. Light-gated molecular brake system based on Pp rotator and the styryl brake pad. Dihedral angle $\theta=$ (C3-C2-C39-C40), $\alpha=(\mathrm{C} 2-\mathrm{C} 39-\mathrm{C} 40-\mathrm{C} 41)$, bond angle $\beta=(\mathrm{C} 2-\mathrm{C} 39-\mathrm{C} 40), \gamma=(\mathrm{C} 41-\mathrm{C} 40-\mathrm{C} 39)$, bond length $d_{1}=$ $(\mathrm{C} 2-\mathrm{C} 39), d_{2}=(\mathrm{C} 39-\mathrm{C} 40), d_{3}=(\mathrm{C} 40-\mathrm{C} 41)$.

\section{COMPUTATIONAL DETAILS}

The DFT and TD-DFT were used to investigate the interestingissues of molecular brake system.The object is a huge conjugation system, which requires proper long-range corrected (LC) functionals to describe correctly. At the same time, the molecule contains several electronegative atoms and different types of non-covalent interaction (NCI), which requests reasonable NCI options to reflect. Based on this, the popular $\omega \mathrm{B} 97 \mathrm{XD}^{[30]}$ functional which includes $100 \%$ long-range exact exchange, empirical dispersion corrections, and so on was an excellent choice for the majority task in this paper.All of the quantum models were created, drawn and exported by GaussView 5.0.8 ${ }^{[31]}$ and VMD 1.9.3 ${ }^{[32]}$ visualization software.

First step, the (Z)-1 and (E)-1 were fully optimized with the acetonitrile solventwas considered at the level of $\omega \mathrm{B} 97 \mathrm{XD} / 6-31 \mathrm{G}(\mathrm{d})^{[33]}$. Then the relaxed potential energy surface scan procedures of $(Z)-1$ and $(E)-1$ were carried out with the dihedral angle (denoted as $\theta$ ) ofC3-C2-C39-C40 as the variable (the stepsize is $5^{\circ}$ ) under the $6-311 \mathrm{G}(\mathrm{d}, \mathrm{p})^{[34]}$ basis set. Except for the corresponding dihedral angle, there are no other restrictions.Second step, the transition state optimization process were performed using the high energy points as initial guesses at the level of $\omega B 97 X D / 6-311 G(d, p)$, and the two stable conformers of $(Z)-\mathbf{1}$ and $(E)-\mathbf{1}$ were alsore-optimized under the 6-311G(d,p) basis set. As a result, the energy barriers of fast and slow rotation would be figured out.In order to investigate the propagatingprogress of double bond during the braking process, third step, without 
any other restricted conditions, the dihedral angle of C2-C39-C40-C41 represented as $\alpha$ was been scanned using relaxed potential energy surface with a stepsize of $5^{\circ}$ at the accuracy of $\omega B 97 X D / 6-311 G(d, p)$.Fourth step, for the aim of understanding the mechanism of photoinduced configuration transformation, starting from the highest energy structure, the unrestricted DFT calculation of Bernyalgorithm ${ }^{[35]}$ were proceeded using the $6-311 G(d, p)$ basis set to obtain the intermediate.Fifth step,for the conformers of $(Z)-\mathbf{1}$ and $(E)-\mathbf{1}$, the time-dependent density functional theory (TD-DFT) method under several functionals were used to calculate the 6 excited state energy levels with solvent to obtain the theoretical UV absorption spectra. And then, the databases were compared to illustrate more convincing conclusions, besides, the excited state databases were also utilized in subsequent natural transition orbital (NTO) and PET analyses using Multiwfn 3.7 $\operatorname{program}^{[36-38]}$. All of the above computations were completed by Gaussian $09^{[39]}$ quantum chemistry package.

\section{RESULTS AND DISCUSSION}

\subsection{Molecular geometry optimization}

The light-driven molecular brake can be recognized as a device which could realize the control of the rotation movement through the conversion of the $\mathrm{C}=\mathrm{C}$ double bond configuration. Therefore, in order to study the braking mechanism of the light-driven molecular brake, the different configurations must be analyzed.In the ground state, the $\mathrm{C}=\mathrm{C}$ double bond in molecule $\mathbf{1}$ has two configurations - ground state $(E)-\mathbf{1}$ and $(Z)-\mathbf{1}$, which can be transformed in a controllable manner at different frequency illuminations. Under gas phase conditions, the initial geometric structure optimizations of the ground states $(E)-\mathbf{1}$ and $(Z)-\mathbf{1}$ were carried out at $\omega \mathrm{B} 97 \mathrm{XD} / 6-31 \mathrm{G}(\mathrm{d})$ level, and the ground state single point energies of the two stereoisomers after optimization were calculated using the method of $\omega \mathrm{B} 97 \mathrm{XD} / \mathrm{def}-\mathrm{TZVP}^{[40]}$, the obtained single-point energies are listed in Table 1. It can be seen from the table that the energy of $(Z)$-type is ca. $6 \mathrm{kcal} \cdot \mathrm{mol}^{-1}$ lower than $(E)$-type.In order to verify the stability of the two isomers, theNCI analyses were performed to visualize the intramolecular NCIsand the reduced density gradient (RDG) isosurface maps (As shown in Figure 1) were drew and exported.It can be figured that the types of NCIs in the two isomers are roughly the same, mainly the van der Waals (vdW) interactions, all the NCIs in the $(E)$-type are very weak. Whereas in the $(Z)$-type configuration, a benzene ring in the styrene moiety are in a dislocation parallel position with a paddle benzene ring in the $\mathrm{Pp}$ (the cyan highlight), the two benzene rings face to face and forming a $\pi \cdots \pi$ stacking effect, which is much stronger than any of the $(E)$-type configuration, further reducing the energy of the system and stabilizing the molecules.Therefore, even if the steric hindrance effect is weak in the $(E)$-type configuration, the $\pi \cdots \pi$ stacking effect of the $(Z)$-type configuration is stronger, making the total energy of the system lower than the $(E)$-type configuration and the molecule becomes more stable. The molecular 
structures of the two configurations are shown in Figure 1, and Table 1 also lists some key parameters of the ground state $(E)-\mathbf{1}$ and $(Z)-\mathbf{1}$ configurations.Due to the existence of NCIs and steric hindrances, the benzene rings on both sides of the $\mathrm{C}=\mathrm{C}$ double bond in $(E)-\mathbf{1}$ and $(Z)-\mathbf{1}$ are not in the same plane. The calculated angle between the planes according to atomic coordinates is ca. $69.53^{\circ}$ in $(E)-1$, while the angle in $(Z)-1$ is about $64.69^{\circ}$, indicating that the conjugated planar structures on both sides of the $\mathrm{C}=\mathrm{C}$ double bond of the two configurations are destroyed to a certain extent, which will affect the intramolecular electron transition and electron transfer properties.

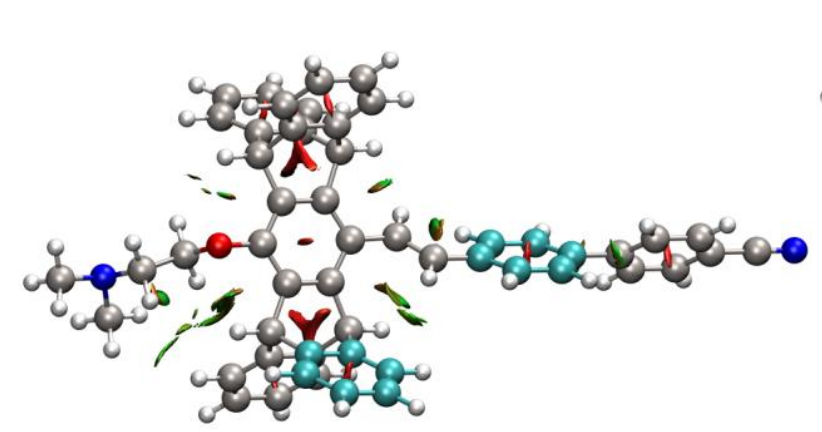

(a) $(E)-\mathbf{1}$

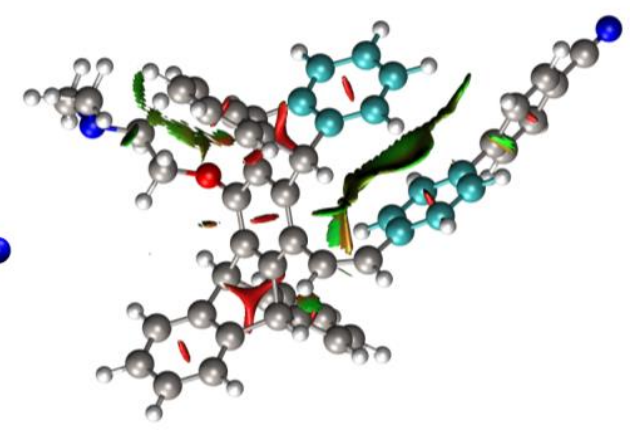

(b) (Z)-1

$\begin{array}{ccc}\text { Strong } & \text { Van der Waals } & 0.02 \\ \text { attraction } & \text { interaction } & \text { Strong } \\ \text { repulsion }\end{array}$

Figure 1. The reduced density gradient (RDG) isosurface map of (a) (E)- and (b) (Z)- configuration of molecule 1.

The white are $\mathrm{H}$, the silver are $\mathrm{C}$, the red are $\mathrm{O}$, the blue are $\mathrm{N}$, the cyan are highlighted $\mathrm{C}$.

Table 1. The important optimized parameters at $\omega \mathrm{B} 97 \mathrm{XD} / 6-31 \mathrm{G}(\mathrm{d})$ level of $(E)-\mathbf{1}$ and $(Z)-\mathbf{1}$ configurations and calculated single-point energies $\left(\varepsilon_{\text {ele }}\right)$ at $\omega \mathrm{B} 97 \mathrm{XD} / \mathrm{def}-\mathrm{TZVP}$.

\begin{tabular}{cccccc}
\hline Config. & $(E)-\mathbf{1}$ & $(Z)-\mathbf{1}$ & Config. & $(E)-\mathbf{1}$ & $(Z)-\mathbf{1}$ \\
\hline Dihedral $\theta /^{\circ}$ & -49.21 & -68.23 & Lengths $d_{1} / \AA$ & 1.476 & 1.484 \\
Dihedral $\alpha /^{\circ}$ & -179.50 & -0.69 & Lengths $d_{2} / \AA$ & 1.340 & 1.339 \\
Angle $\beta /^{\circ}$ & 123.54 & 126.71 & Lengths $d_{3} / \AA$ & 1.470 & 1.475 \\
Angle $\gamma /^{\circ}$ & 126.43 & 128.16 & $\begin{array}{c}\varepsilon_{\mathrm{ele}} / \times 10^{6} \\
\mathrm{kcal} \cdot \mathrm{mol}^{-1}\end{array}$ & -1.39833448 & -1.39834041 \\
\hline
\end{tabular}

\subsection{Minimum energy profiles and thermodynamic properties}

The rotation process would theoretically produce countless conformations, each of which has different physical and chemical properties, and some of them are the most specific.In order to investigate the dynamic features and operating mechanism of the rotational motion of the molecular brake, it is necessary to analyze these conformations. Starting from the two optimized configurations $(E)-\mathbf{1}$ and $(Z)-\mathbf{1}$, respectively, the dynamic characteristics of the two configurations are studied by the method of relaxed potential energy surface scanning. The scanning results of the single-bond rotating dihedral angle are shown in Figure 2. It can be seen that the MEP of 
(E)-configuration is relatively smooth, and there is no obvious sudden drop in potential energy. The energy difference between the highest and lowest energy points is ca. $6 \mathrm{kcal} \cdot \mathrm{mol}^{-1}$, according to statistical thermodynamics, It is considered that this value is in the free rotation interval ${ }^{[8,41-43]}$, indicating that the rotation of the single bond is relatively free, and it is not restricted by too much resistance, thus, it is in a state of rapid rotation (OFF in Scheme 1).In addition, the relative free energies of the four stable conformations (A, C, E, and $\mathbf{G})$ of $(E)$-configuration are $0.14,0$ (reference point), 0.44 , and $0.35 \mathrm{kcal} \cdot \mathrm{mol}^{-1}$, respectively, it is obvious that the difference is small (the conformational isomerism caused by the side chain of the $\mathrm{C}-\mathrm{O}$ bond is not considered, the same below). It can be seen that the relation between the relative position of the side chain of the aminoalkyl and styrene moiety of $(E)$-configuration has little effect to free energy, because the styrene moiety and the side chain of the aminoalkyl are far apart, which is not enough to generate mutual influence.However, the MEP of $(Z)$-configuration has two obvious potential energy sudden drops $(\mathbf{J} \rightarrow \mathbf{K}, \mathbf{M} \rightarrow \mathbf{N})$, and the energy difference between the highest and lowest energy points rises to ca. $20 \mathrm{kca} \cdot \mathrm{mol}^{-1}$, in stereochemistry, it is considered to be in the range of hindered rotation ${ }^{[8,41-43]}$, and the rotation of single bonds are largely forbidden. The styrene brake pad is inserted between the Pp paddle, and the rotation resistance increases sharply, thereby, the rotation motion becomes slow or even stops, as a result, it is in the state of slow rotation ( $\mathbf{O N}$ in Scheme1).There is a certain differences in the stable conformational energy of $(Z)$-configuration. With the lowest energy conformation $\mathbf{L}$ as the reference point, the relative free energies of $\mathbf{I}, \mathbf{N}$ and $\mathbf{Q}$ are 1.72, 1.24, and $0.70 \mathrm{kcal} \cdot \mathrm{mol}^{-1}$, respectively, therefore, $(Z)$-configuration has four stable conformations.Due to the relatively close distance between the styrene moiety and the side chain of the aminoalkyl, the interaction could be generated, which further reduces the free energy of the system and the molecule becomes more stable.

Specifically, in $(E)$-configuration, due to the styrene moiety extending from the $\mathrm{C} 2$ position of Pp to the side away from Pp (as shown in Figure 3 (a)), during the rotation of the C2-C39 and C-O single bond, it will not cause a significant change in the distance between styrene moiety and aminoethyl, of course,the interaction will no change as well. Therefore, the free energy of each conformation point in the rotation process is basically the same.The styrene moiety in the (Z)-configuration is inserted transversely between the Pp paddles (as shown in Figure 3 (b)). Due to the effect of space resistance, the $\mathrm{C} 2-\mathrm{C} 39$ single bond is not easy to rotate, but it is going back and forth betweenthe two blades (vibration). However, the C-O single bond is not affected by resistance. In the process of rotation, the carbon chain plane and styrene plane will form four limit positions of nearly $0^{\circ}$ (cis coplane), $90^{\circ}, 180^{\circ}$ (trans coplane), and $270^{\circ}$, making the distance between styrene moiety and aminoethyl also varies greatly. Therefore, the interaction will also vary greatly. The free energy of each conformation point will not be the same, and four stable conformations (I, L, N, and Q) will be located. 


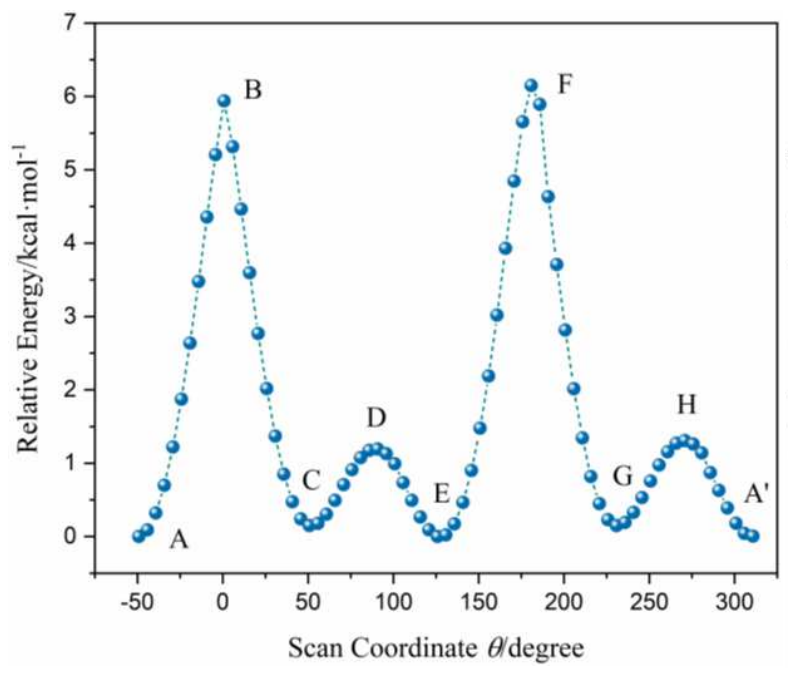

(a)

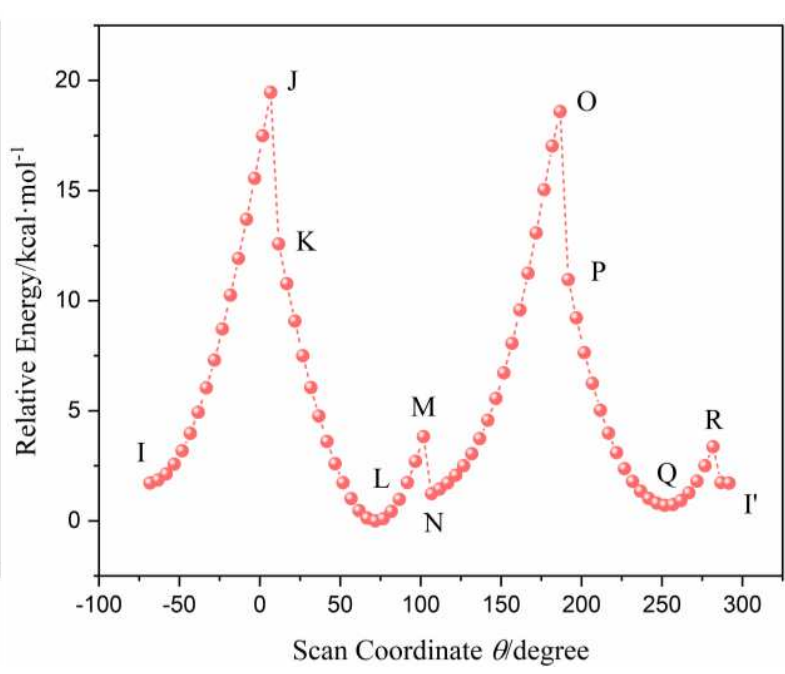

(b)

Figure 2. (a) Minimum energy profile of configuration (E)-1 regarding dihedral angle $\theta$, and (b) minimum energy profile of configuration (Z)-1 regarding dihedral angle $\theta$.

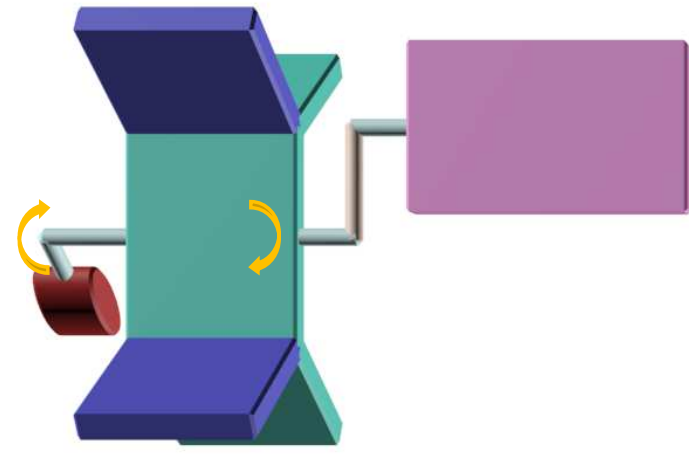

(a)

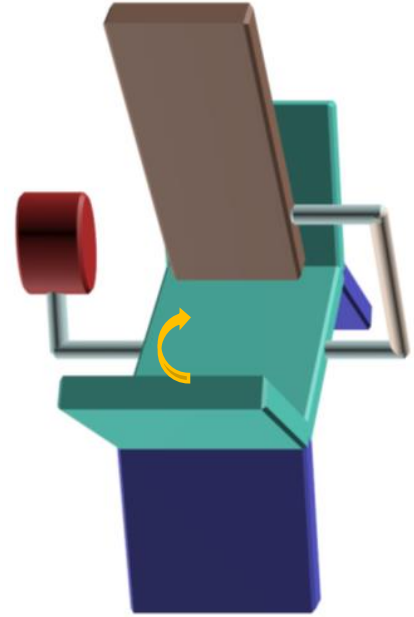

(b)

Figure 3. (a) Macro model diagram of (E)-1, and (b) macro model diagram of (Z)-1.

The thermodynamic quantities of several special conformations are listed in Table 2. Among them, the thermodynamic correction amounts were derived from the frequency calculation tasks including zero-point energy (ZPE) correction (the correction scale under the combination of $\omega \mathrm{B} 97 \mathrm{XD} / 6-311 \mathrm{G}(\mathrm{d}, \mathrm{p})$ is $\left.0.957^{[44-46]}\right)$.

Table 2. Camputed value of thermodynamic quantities for several special conformations.

\begin{tabular}{cccccc}
\hline Config. & Confor. & $\begin{array}{c}\varepsilon_{\mathrm{ele}}{ }^{[\mathrm{a}]} / \times 10^{6} \\
\mathrm{kcal} \cdot \mathrm{mol}^{-1}\end{array}$ & $\begin{array}{c}H_{\mathrm{corr}}{ }^{[\mathrm{b}]} / \\
\mathrm{kcal} \cdot \mathrm{mol}^{-1}\end{array}$ & $\begin{array}{c}G_{\mathrm{corr}}{ }^{[\mathrm{c}]} / \\
\mathrm{kcal} \cdot \mathrm{mol}^{-1}\end{array}$ & $\begin{array}{c}G / \times 10^{6} \\
\mathrm{kcal} \cdot \mathrm{mol}^{-1}\end{array}$ \\
\hline & $\mathbf{A}$ & -1.39833448 & 501.43 & 419.43 & -1.39791504 \\
$(E)-\mathbf{1}$ & $\mathbf{B}$ & -1.39832856 & 501.07 & 420.80 & -1.39790776 \\
& $\mathbf{C}$ & -1.39833436 & 501.46 & 419.18 & -1.39791518 \\
\hline
\end{tabular}




\begin{tabular}{cccccc}
\hline & $\mathbf{D}$ & -1.39833326 & 500.73 & 419.56 & -1.39791369 \\
& $\mathbf{E}$ & -1.39833446 & 501.45 & 419.72 & -1.39791475 \\
& $\mathbf{F}$ & -1.39832839 & 501.04 & 420.22 & -1.39790817 \\
& $\mathbf{G}$ & -1.39833437 & 501.53 & 419.53 & -1.39791484 \\
& $\mathbf{H}$ & -1.39833319 & 500.72 & 419.66 & -1.39791353 \\
& $\mathbf{I}$ & -1.39833910 & 501.71 & 421.69 & -1.39791741 \\
& $\mathbf{T S 1}$ & -1.39832303 & 501.15 & 422.32 & -1.39790071 \\
& $\mathbf{L}$ & -1.39834041 & 501.59 & 422.02 & -1.39791839 \\
& $\mathbf{M}$ & -1.39833677 & 501.48 & 419.94 & -1.39791683 \\
$(Z)-\mathbf{N}$ & $\mathbf{N}$ & -1.39833940 & 501.53 & 421.12 & -1.39791828 \\
& TS2 & -1.39832300 & 501.09 & 422.16 & -1.39790084 \\
$\mathbf{Q}$ & -1.39833998 & 501.57 & & 421.59 & -1.39791839 \\
$\mathbf{R}$ & -1.39833727 & 501.57 & & 421.48 & -1.39791579 \\
\hline
\end{tabular}

[a]: Calculated value of single point energy at $\omega \mathrm{B} 97 \mathrm{XD} / \mathrm{def}-\mathrm{TZVP}$ level.

[b], [c]: Refer to the thermodynamic enthalpy and free energy correction value at the level of $\omega \mathrm{B} 97 \mathrm{XD} / 6-311 \mathrm{G}(\mathrm{d}, \mathrm{p})$, respectively.

It can be seen from the MEPs that there is no obvious energy sudden drop in $(E)$-1. At room temperature, it is almost in a state of free rotation. The rotation energy barrier is calculated from the difference between the highest and lowest free energy points in the first half of the cycle and the second half of the cycle, respectively. They are $7.29 \mathrm{kcal} \cdot \mathrm{mol}^{-1}$ and $6.58 \mathrm{kcal} \cdot \mathrm{mol}^{-1}$. Yet, in (Z)-1, there are two obvious energy sudden drops at point $\mathbf{J}$ and $\mathbf{O}$, respectively, indicating that there are rotating transition states near point $\mathbf{J}$ and $\mathbf{O}$. Therefore, taking these points as the initial structures of the transition states, the transition state search tasks were performed at $\omega \mathrm{B} 97 \mathrm{XD} / 6-311 \mathrm{G}(\mathrm{d}, \mathrm{p})$ accuracy.The calculated result is that both structures have unique imaginary frequencies, which are $26.69 \mathrm{~cm}^{-1}$ and $23.50 \mathrm{~cm}^{-1}$, respectively. The thermodynamic quantities of the two transition states are also listed in Table 2 and their free energies are almost equal.The transition state structures are verified by the intrinsic reaction coordinates (IRC) calculation. The molecular structures of the two transition states are shown in Figure 4, and the key structural parameters of the transition states are given in Table 3. The IRC curves (Figure 5) of the two transition states are smooth, and they can connect the two different conformations forward and backward the transition state. The results of the transition state search show that the styrene moiety and the intersection line of the Pp paddle forms a point-to-point spatial structure, that is, the planarity of the styrene moiety is broken again, which causes a sharp increase in energy.The rotational transition state is extremely unstable, thus, itwouldquickly adjust the structure to release energy and form a stable conformation. At this time, 
the probability of the styrene moiety rotating to both sides is almost the same, so the ratios of forming two different conformations will theoretically be the same. The free energies of the transition states werefigured outvia the single-point energies and the free energy correction amounts calculations. Based on these data, the rotational energy barriers can also be derived from the difference between the free energies of the transition states and the free energies of the lowest points, which are 17.68 and $17.55 \mathrm{kcal} \cdot \mathrm{mol}^{-1}$, respectively.

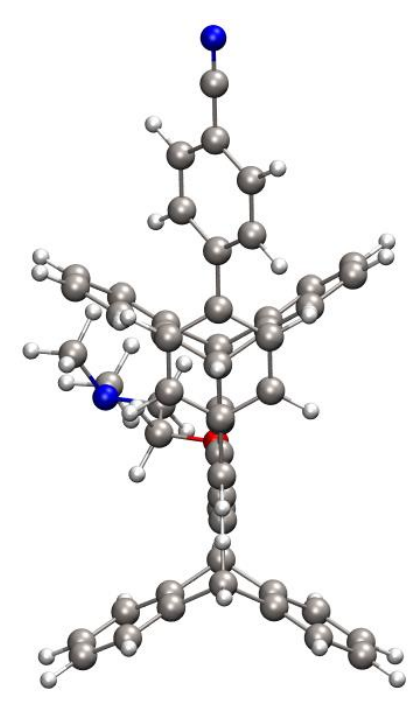

(a) TS1

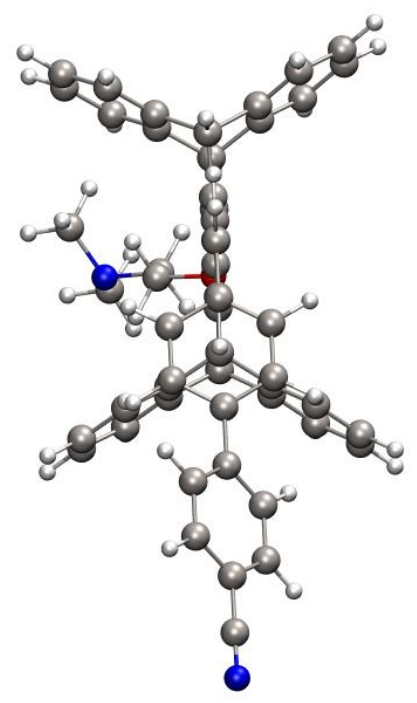

(b) TS2

Figure 4. The molecular structure of the two rotating transition states: (a) TS1 and (b) TS2 of (Z)-1.
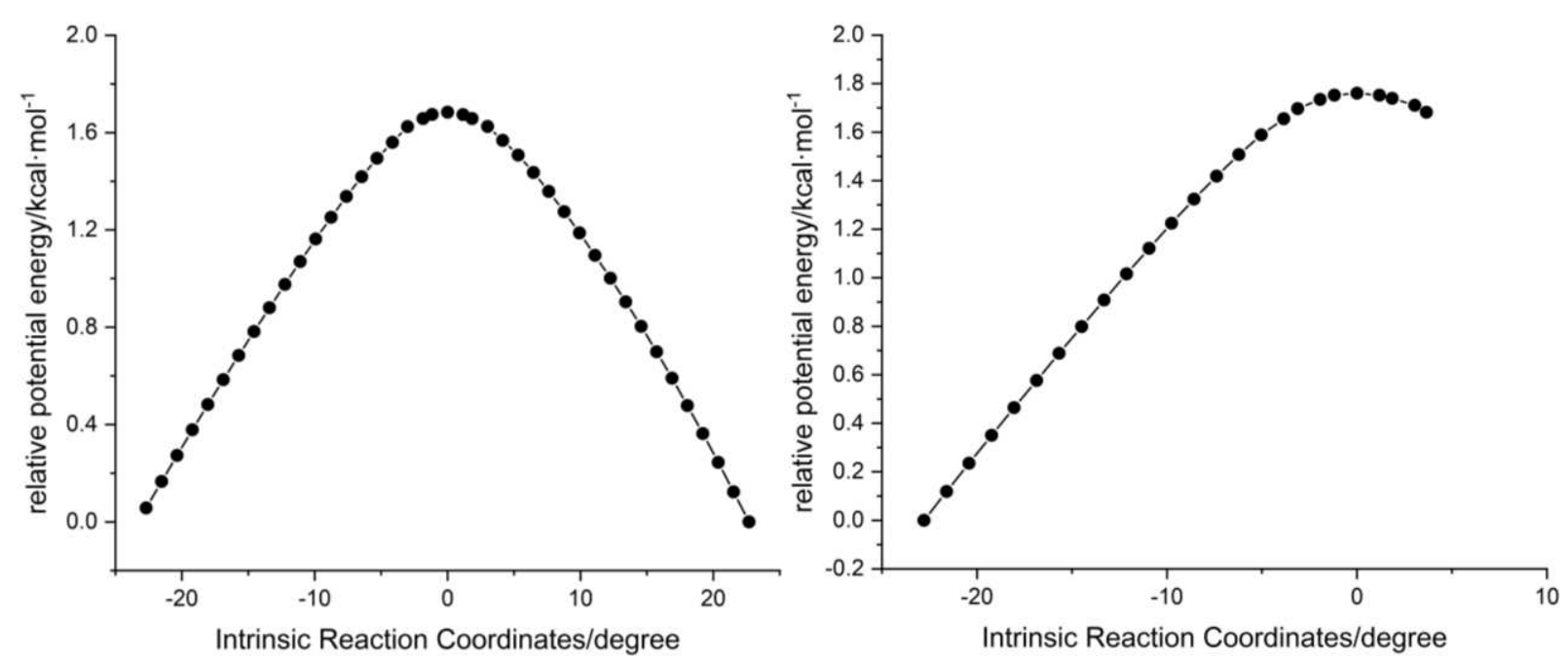

Figure 5. The intrinsic reaction coordinates (IRC) curves for (a) TS1, and (b) TS2 of (E)-1 during rotation. 
Table 3. Calculated structural parameters of rotating transition states TS1 and TS2.

\begin{tabular}{cccccc}
\hline Constr. & TS1 & TS2 & Constr. & TS1 & TS2 \\
\hline Dihedral $\theta /^{\circ}$ & -0.62 & 179.70 & Angle $\gamma /{ }^{\circ}$ & 134.34 & 134.33 \\
Dihedral $\alpha /^{\circ}$ & 0.33 & 0.21 & Lengths $d_{1} / \AA$ & 1.483 & 1.483 \\
C39-C40-C41-C42 & 90.60 & -93.77 & Lengths $d_{2} / \AA$ & 1.340 & 1.340 \\
Angle $\beta /^{\circ}$ & 140.50 & 140.51 & Lengths $d_{3} / \AA$ & 1.481 & 1.481 \\
\hline
\end{tabular}

In summary, the rotation mechanism of $(E)-\mathbf{1}$ and (Z)-1 can be described as (a) and (b) in Figure 6, respectively, where $\mathbf{A}-\mathbf{H}, \mathbf{I}, \mathbf{L}, \mathbf{M}, \mathbf{N}, \mathbf{Q}$ and $\mathbf{R}$ are the macroscopic models of different conformations during the rotation of $(E)-\mathbf{1}$ and $(\mathbf{Z})-\mathbf{1}$, respectively. TS1 and TS2 are the macroscopic models of the two transition states that appear during the $360^{\circ}$ rotation of $(Z)-1($ the atom coordinates of them are supplied by Supporing Information (SI)). The conformation $\mathbf{K}$ and $\mathbf{P}$ are the same in structure as the conformations $\mathbf{L}$ and $\mathbf{Q}$, reflected on the potential energy surface, they are just not optimized to the local minimum energy point.

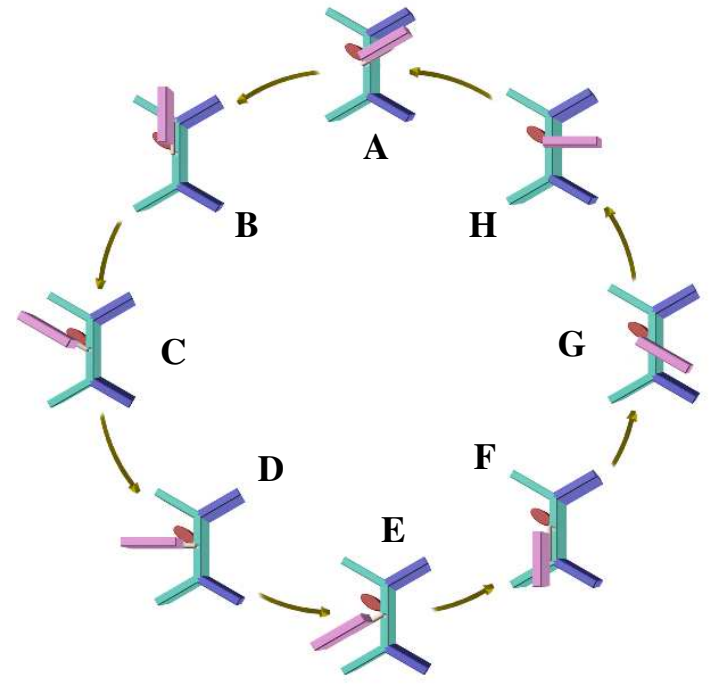

(a) $(E)-\mathbf{1}$

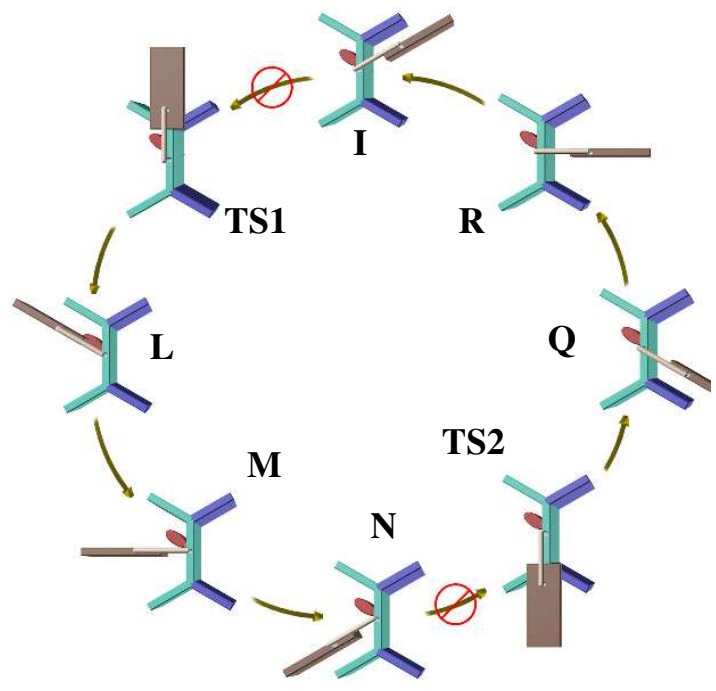

(b) $(Z)-1$

Figure 6. (a) $360^{\circ}$ rotation mechanism diagram of $(E)-\mathbf{1}$, and (b) $360^{\circ}$ rotation mechanism diagram of (Z)-1.

\subsection{Electron transfer}

The photoinduced electron transfer (PET) process is closely related to the electronic excitation and transition of molecules. It is involved to the differences in electronic structure between the excited states and the ground states. For the analyses of electronic excitation and transition, a more accurate and convenient method of natural transition orbitals (NTOs) can be used.The electronic transition is essentially a transition between a certain electronic state and another electronic state of the system. In order to facilitate the understanding and study of the transition mode, the electronic transition is usually described as the model of the transition of an occupied orbital electron to a 
certain non-occupied orbital. When calculating the molecular excited state, the transition mode can be expressed as a linear combination of different transition forms between occupied orbitals and non-occupied orbitals of the ground states, and the contribution rate of one or several transitions to the total transition is dominant, this transition model is NTO.In order to investigate the electron transfer characteristics of the molecular brake system, under the $\omega$ B97XD/def-TZVP level and solvent (acetonitrile) condition, the ground states and excited states were theoretical computed by DFT and TD-DFT respectively,thereby, the NTOs of the ground states and excited states were obtained. Because the photoisomerization reaction is a singlet excited state reaction in the absence of other photosensitizers, and it is a reaction in the first excited state ${ }^{[17]}$, therefore, only the first excited state S1 was considered when the NTOs analyses were performed.Figure 7 shows the dominant NTO model diagrams and points out the percentage of such transition modes in the electronic transition components. It can be seen from the figure that the NTOs of $(E)-\mathbf{1}$ and $(Z)-\mathbf{1}$ are basically distributed in the conjugated part, that is, the conjugate bridge partthat connected by the Pp center benzene-styrene-benzene-cyano group. The ether bond oxygen has a lone pair of electrons and forms a $p-\pi$ conjugate effect with the $\pi$-conjugated chain, as a result, there will be a certain orbital distribution on the oxygen. The distributions of aminoethyl chian and Pp paddle benzene rings are less, it is because aminoethyl is a single bond of $\sigma$, the energy level is very high, it is not prone to electronic transitions and difficult to participate in the transmission of electrons, however, it can expand the delocalization range of electrons and plays a role in promoting the electronic transitions. The paddle benzene ringsare also difficult to participate in the transitions due to the isolation of the $\sigma$ single bond structure of bridge ring.It can also be figured that the two modes that contribute the most to the electronic transitions of $(E)-\mathbf{1}$ and (Z)-1 are $\pi \rightarrow \pi^{*}$ transitions, which are the transitions from No. 190 to No. 191 orbital and No. 189 to No. 192 orbital, respectively. The contributions of these two transitions to the excited states of $(E)-\mathbf{1}$ and $(Z)-\mathbf{1}$ are $92.82 \%, 93.25 \%$, $5.89 \%$, and $5.61 \%$, respectively, of which the No. $190 \rightarrow$ No. 191 transition accounts for absolutely dominant. The above results show that no matter $(E)-\mathbf{1}$ or $(Z)-\mathbf{1}$, a similar intramolecular electron transfer process would occur.

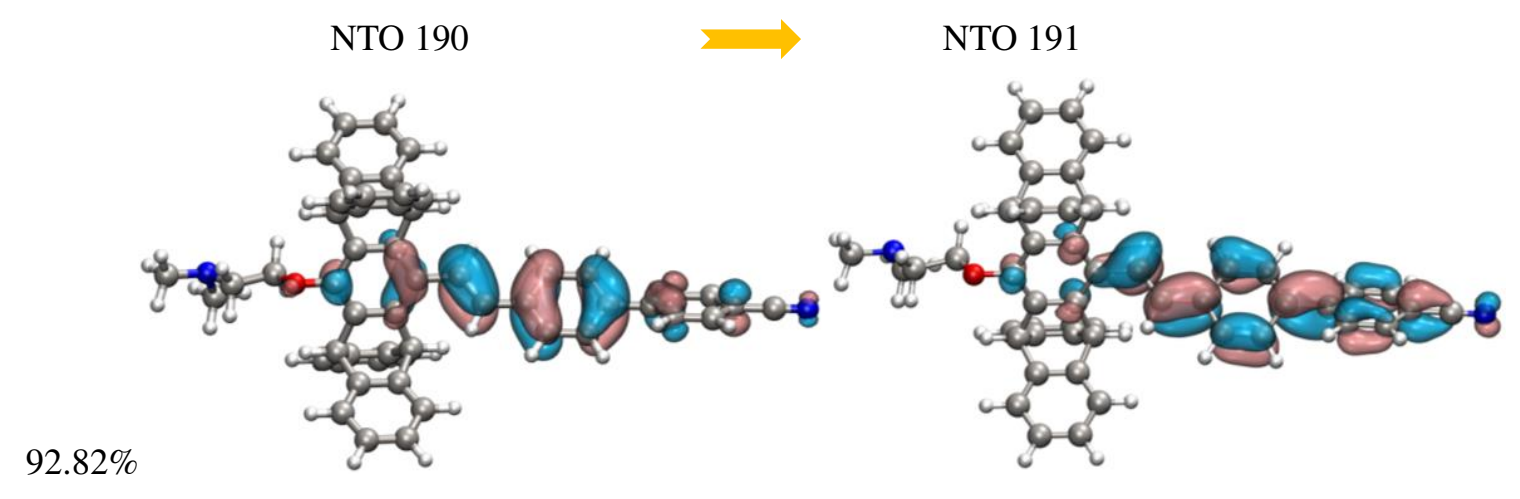




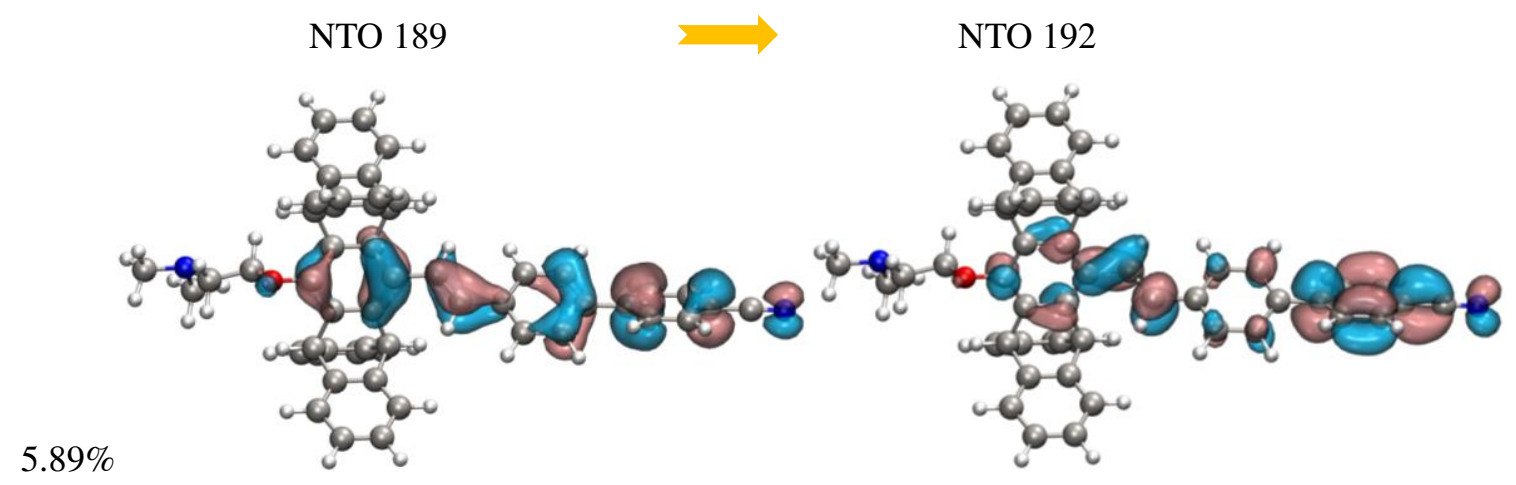

(a) NTO diagrams of (E)-1
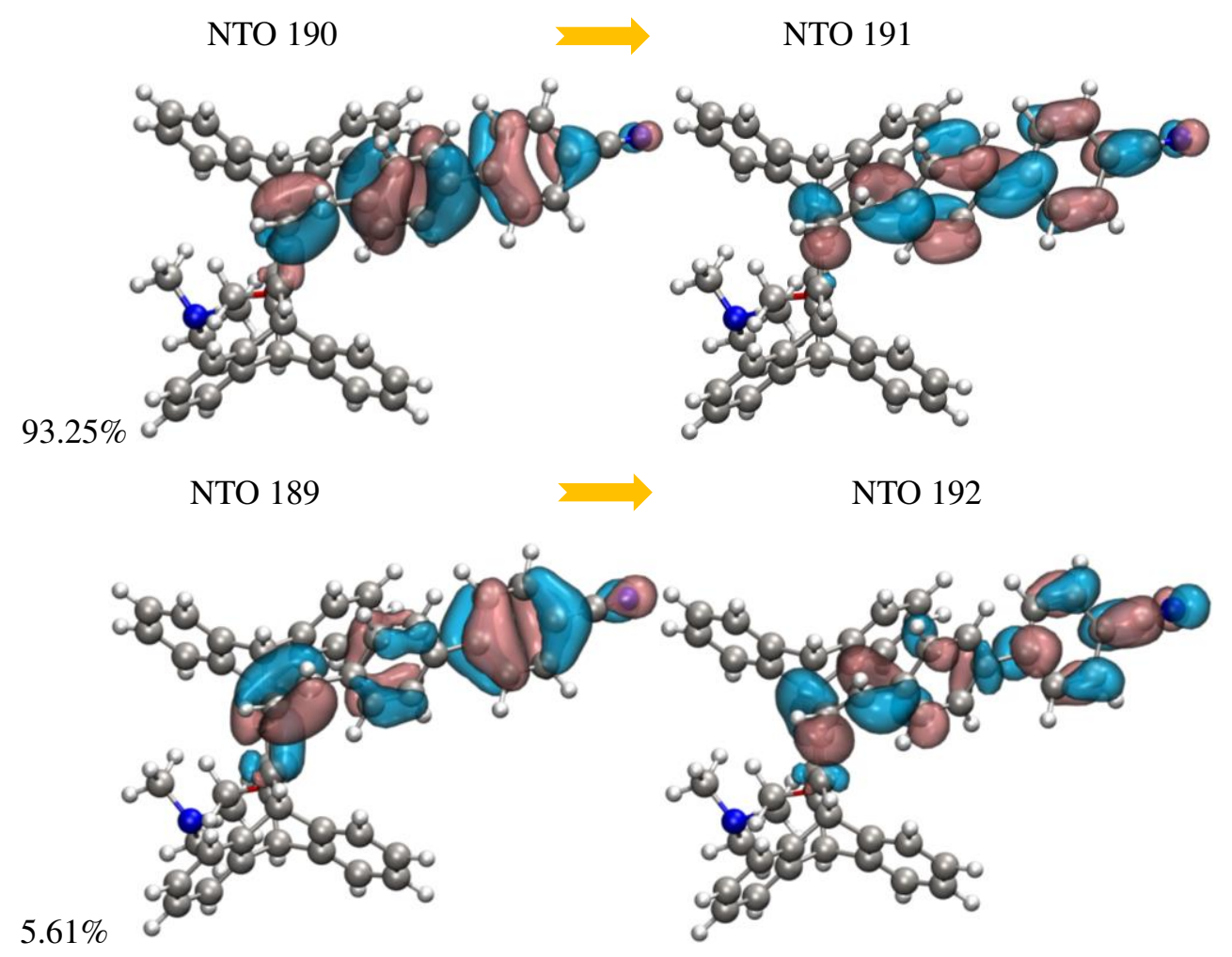

(b) NTO diagrams of (Z)-1

Figure 7. The dominant and sub-dominant natural transition orbital models of (a) (E)-1, and (b) (Z)-1.

For the purpose of further clarifying the characteristics of electron transfer, the charge density defference (CDD) analyses between the excited states and the ground states were carried out, the CDD isosurface diagrams are shown as Figure 8. Among them, the green area is the place where the electron density increases after excitation, and the blue represents the place where the electron density decreases.It can be seen that in $(E)-\mathbf{1}$ and $(Z)-\mathbf{1}$, the electrons are still concentrated in the conjugated part, and due to the auxiliary effect of the aminoethyl chain, the electron activity range is expanded, and almost penetrating all of the conjugated parts, and what is worth to note is that the type of electronically excited transition is $\pi \rightarrow \pi^{*}$ transition. The final results of electron transfer are: the electrons in $(E)-\mathbf{1}$ are transferred from the benzene in the center of the $\mathrm{Pp}$ to the 
cyano-substituted phenylstyrene, whilethe electrons in $(\mathrm{Z})-1$ are transferred from the $\mathrm{C}=\mathrm{C}$ double bond to the cyano group.The reason for it is that the ethylenic double bond and the Pp center benzene are not in the same plane because of the (Z)-type steric hindrance effect, thence, destroyed the conjugation of the chain and shortens the conjugate bridge, which reduces the electron distribution on the $\mathrm{Pp}$ center benzene. In contrast, the electron distribution of the $\mathrm{C}=\mathrm{C}$ double bond increases.In conclusion, the two are almost the same in transfer mode, but there is a slight difference in the position of electron transfer.

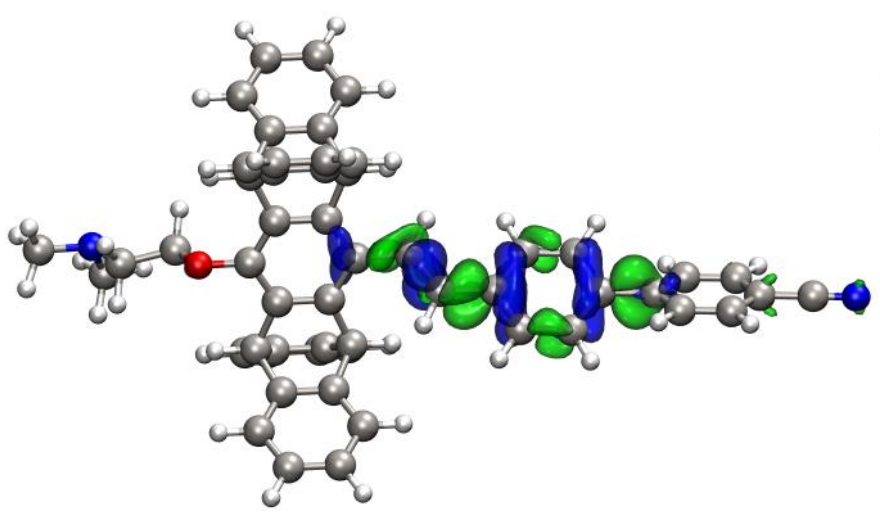

(a)

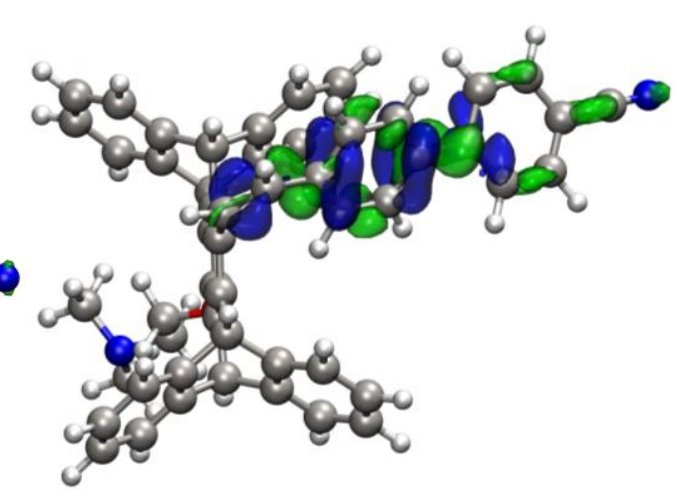

(b)

Figure 8 . The charge density difference (CDD) between the computed excited state (S1) and the ground state of (a) $(E)-\mathbf{1}$, and (b) (Z)-1. The green is where the electron density increases, while the blue is where the electron density decreases.

\subsection{Ultraviolet absorption spectrum}

Due to the long-range conjugated structure in the molecules, the two isomers can absorb ultraviolet light ${ }^{[17]}$. Based on the optimized structures of $(E)-\mathbf{1}$ and $(Z)-\mathbf{1}$, four different functionals of $\omega \mathrm{B} 97 \mathrm{XD}^{[30]}$, M06-2X ${ }^{[47]}, \mathrm{BMK}^{[48]}$, and CAM-B3LYP ${ }^{[49]}$ are combined with TD-DFT, respectively,using the def-TZVP base set, the lowest vertical excitation energies of the two stereoisomers were calculated under acetonitrile solvent conditions.Figure 9shows the theoretical simulation electronic absorption spectra of $(E)-\mathbf{1}$ and (Z)-1 under different functionals. Table 4 supplies the key data of the absorption spectra. It is obvious that the characteristic absorption wavelengths of the two isomers range from $260 \mathrm{~nm}$ to $400 \mathrm{~nm}$, and the shapes of the absorption peaks of the two isomers are also very similar.The characteristic absorption wavelengths of $(E)-\mathbf{1}$ under the four functionals are $311,315,324$, and $317 \mathrm{~nm}$, noticing, the experimental value is 320 $\mathrm{nm}^{[17]}$. It can be seen from the data that the characteristic absorption peaks are mainly contributed by $\mathrm{S} 0 \rightarrow \mathrm{S} 1$ excitation, and the vibrator intensities $f$ are very high.According to the refrences ${ }^{[17]}$, the isomerization reaction occurs in the $\mathrm{S} 1$ excited states, and the $\mathrm{S} 0 \rightarrow \mathrm{S} 1$ excitation corresponds to the characteristic absorption peaks on the spectra. Therefore, the characteristic absorption peaksof $(E)-1$ can be attributed to the $\pi \rightarrow \pi^{*}$ trasitionsin direction of the Pp center benzene to phenylstyrene (Figure 7).Owing to undergoing the expanded conjugate bridge, the energy level of electron 
transitions are not high, and the characteristic peaks are near of ultraviolet region. This is the most major transition mode of the $(E)$-type configutation, hence the absorption intensity is also strong, the width of half-peak is also relatively large.Compared with $(E)-\mathbf{1}$, the absorption wavelength range of (Z)-1 is narrowed (270-360 nm). Specifically, using four type functionals, the computed characteristic absorption wavelengths mainly caused by S0 $\rightarrow \mathrm{S} 1$ excitation are291, 295, 302, and $296 \mathrm{~nm}$, and the experimental results are $309 \mathrm{~nm}^{[17]}$, thus, the redshift under the same functional is ca. $20 \mathrm{~nm}$, in addition, the absorption intensity is also reduced nearly $25 \%$. The reason is that after the $(E)$-type is isomerized to the $(Z)$-type, the coplanarity between the ethylenic double bond and the benzene in the $\mathrm{Pp}$ center is broken, and the dihedral angle $\theta$ between the two planes is $71.06^{\circ}$ (absolute value, the one of $(Z)$-type is $48.54^{\circ}$ ). The result is that the conjugation of the molecule is destroyed, and the conjugate bridge that promotes electron transition and transfer is partially blocked, which makes the $\pi \rightarrow \pi^{*}$ transitionof Pp center benzene to phenylstyrene more difficult,instead, it becomes the $\pi \rightarrow \pi^{*}$ transition from the $\mathrm{C}=\mathrm{C}$ double bond to cyanobenzene. The electron delocalization is weakened due to the shortening of the conjugate bridge, and the excitation energy is increased. Therefore, the absorption wavelength will shift to the shortwave direction.As for the decrease in absorption intensity, it may be because the formation of $\pi \cdots \pi$ stacking in (Z)-type configuration, which leads to a more compact molecular structure, resulting in a decrease in absorbance.In compared, it is noticed that the characteristic absorption wavelengths calculated using the BMK functional is closer to the experimental value. For $(E)-\mathbf{1}$ and $(Z)-\mathbf{1}$, the calculation errors are:

$$
\begin{gathered}
\delta_{(Z)-1}^{\mathrm{BMK}}=\frac{324-320}{320} \times 100 \%=+1.25 \% \\
\delta_{(E)-1}^{\mathrm{BMK}}=\frac{302-309}{309} \times 100 \%=-2.27 \%
\end{gathered}
$$

The accuracy is already very good. The other three errors are listed in Table 4 . The error of $(Z)-\mathbf{1}$ is generally larger than that of $(E)$-1, which may have a great relation with the compactness of the molecular structure. Thence, for the spectral simulation of the large conjugate system, among the four functionals, the BMK functional has the best performance, which is also mentioned in the refrence ${ }^{[50]}$.In summary, the (E)-type has better conjugation than the (Z)-type,so the main form of electronic transition $(\mathrm{S} 0 \rightarrow \mathrm{S} 1)$ that promotes the isomerization reaction is easier to proceed. In other words, (E)-type conversion to $(Z)$-type is easier than (Z)-type to $(E)$-type, and the required radiation wavelength is shorter.These computational results and conclusions are in good agreement with the experimental results ${ }^{[17]}$. 


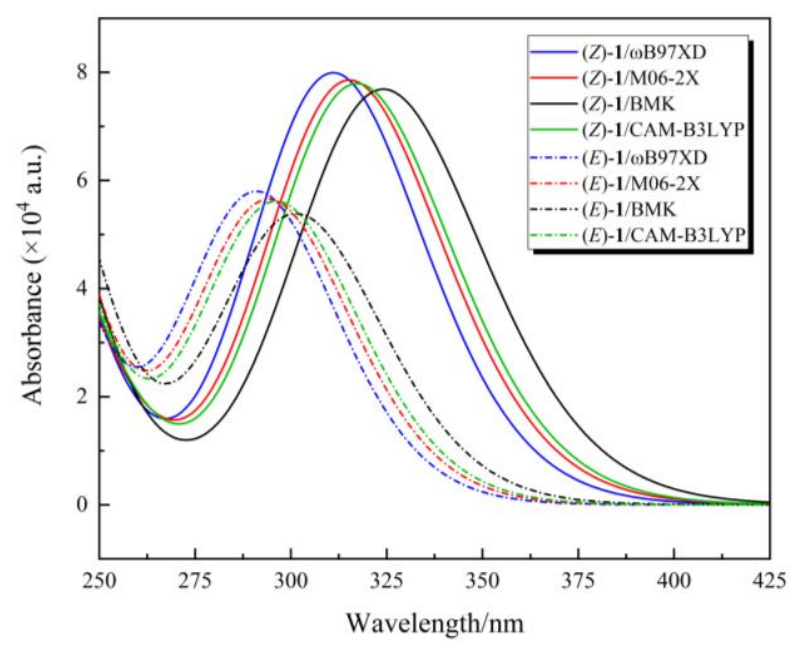

Figure 9. The absorption spectra of $(E)-\mathbf{1}$ and $(Z)-\mathbf{1}$ simulated by different functionals in solvent of acetonitrile.

Table 4. The characteristic absorption (S0-S1) spectrum data table of (E)-1 and (Z)-1 camputed by different functional.

\begin{tabular}{|c|c|c|c|c|c|c|}
\hline Config. & Functional & $E_{\mathrm{ex}} / \mathrm{eV}$ & $f^{[\mathrm{a}]}$ & $\lambda_{\max } / \mathrm{nm}$ & Error $^{[\mathrm{b}]} / \%$ & Configuration ${ }^{[c]}$ \\
\hline \multirow{4}{*}{$(E)-\mathbf{1}$} & $\omega B 97 X D$ & 3.98 & 1.97 & 311 & -2.81 & $\mathrm{~N} 190 \rightarrow 191(92.82 \%)$ \\
\hline & M06-2X & 3.93 & 1.93 & 315 & -1.56 & $\mathrm{~N} 190 \rightarrow 191(95.56 \%)$ \\
\hline & BMK & 3.82 & 1.89 & 324 & +1.25 & N $190 \rightarrow 191(96.92 \%)$ \\
\hline & CAM-B3LYP & 3.91 & 1.92 & 317 & -0.94 & $\mathrm{~N} 190 \rightarrow 191(94.36 \%)$ \\
\hline \multirow{4}{*}{$(Z)-1$} & $\omega \mathrm{B} 97 \mathrm{XD}$ & 4.26 & 1.42 & 291 & -5.83 & $\mathrm{~N} 190 \rightarrow 191(93.25 \%)$ \\
\hline & M06-2X & 4.21 & 1.38 & 295 & -4.53 & N $190 \rightarrow 191(95.84 \%)$ \\
\hline & BMK & 4.11 & 1.31 & 302 & -2.27 & N $190 \rightarrow 191(97.18 \%)$ \\
\hline & CAM-B3LYP & 4.18 & 1.38 & 296 & -4.21 & N $190 \rightarrow 191(94.78 \%)$ \\
\hline
\end{tabular}

[a]: The $f$ refers to the vibrator intensity.

[b]: Refers to the relative error compared with the experimental value.

[b]: N stands for Natural Transition Orbital (NTO).

\subsection{Isomerization reaction}

In order to study the dynamic properties of the isomerization reaction, the relaxed potential energy surface scanning calculation of the $\mathrm{C}=\mathrm{C}$ double bond is required.With $(E)$-type as the initial structure, the $\omega \mathrm{B} 97 \mathrm{XD} / 6-311 \mathrm{G}(\mathrm{d}, \mathrm{p})$ method was applied to implement the 36-step in total (stepsize is $5^{\circ}$ ) scaning task. The obtained MEPof double bond is shown asFigure 10 (a). The figure shows that there is an obvious energy sudden drop from point $p$ to $p+1$, indicating that there is a transition state near the $\mathrm{p}$ point.Regarding $\mathrm{p}$ as the initial guess structure and keeping basis set same, the U $\omega$ B97XD functional was used for transition state optimization (Gas phase), where $U$ stands for unrestricted calculation. The reason isthat during the process of double bond rotation, the issue of $\pi$ bond destruction (opening) is involved, so that the system would be a certainnature similar to 
radicals, consequently, the restricted calculations will be unreasonable. The optimization result is shown in Figure 10(b). In the optimized structure, the dihedral angle $\alpha$ (C2-C39-C40-C41), which is also called the twist angle is $-87.43^{\circ}$. That is, the planes of the atoms on both sides of the $\mathrm{C}=\mathrm{C}$ double bond are almost perpendicular to each other.The unique imaginary frequency of the transition state is $579.13 \mathrm{~cm}^{-1}$, and the vibration modesare the twisting motions of the $\mathrm{C}-\mathrm{H}$ bond with the line where the double bond carbon is located as the axis (as shown by the arrow in Figure 10 (b)). If it is vibrated in the manner (i), it will finally be transformed into a (Z)-configuration, and if it is vibrated in the manner (ii), the product will be the $(E)$-configuration. The transition state is a very unstable structure, which will undoubtedly lead to an increase in the energy of the system.The single-point energy calculated using the def-TZVP basis set for this structure is $\varepsilon_{\text {ele }}=$ $-1.39829072 \times 10^{6} \mathrm{kcal} \cdot \mathrm{mol}^{-1}$, and the free energy correction value calculated at the $6-311 \mathrm{G}(\mathrm{d}, \mathrm{p})$ basis set is $422.00 \mathrm{kcal} \cdot \mathrm{mol}^{-1}$. Based on this, the energy barrier $\Delta G_{E-Z}$ of the $(E)-\mathbf{1} \rightarrow(Z)-\mathbf{1}$ isomerization process is calculated to be $42.75 \mathrm{kcal} \cdot \mathrm{mol}^{-1}$, and the barrier $\Delta G_{Z-E}$ of the reverse isomerization process from $(Z)-\mathbf{1} \rightarrow(E)-\mathbf{1}$ is $45.96 \mathrm{kcal} \cdot \mathrm{mol}^{-1}$.In order to verify the transition state, the IRC (Figure 11) was computated using the 6-311G(d,p) basis set. The IRC curve can continuously and smoothly connect the product $((Z)-\mathbf{1})$ and the reactant $((E)-\mathbf{1})$, revealing that the optimized vertical transition state is the ground state intermediate $\mathrm{p}^{\neq[17]}$ of photoisomerization reaction.Because the intermediate is a saddle point on the S0 potential energy surface, the probability of its evolution to both sides is almost equal.That is, the molecule is excited to the S1 state, and after structural relaxation and evolution to $\mathrm{p}^{*}$, it releases energy and transitions back to the ground state intermediate $\mathrm{p}^{\neq}$. When the structure relaxes to steady state, the probability of propagating to the product direction and the reactant direction is almost 50/50. This does not mean that the yields of $(E)$-type $\rightarrow(Z)$-type or $(Z)$-type $\rightarrow(E)$-type photoisomerization reactions are equal.Because for most such reactions, the energy level relations between the structures on the S1 potential energy surface corresponding to the product, the reactant, the excited state intermediate $\mathrm{p}^{*}$, and the ground state intermediate $\mathrm{p}^{\neq}$are not certain.In other words, the relations between the energy of product and the reactant, and $h v_{1}, h v_{2}$ are not easy to determine (shown in Figure 12).Most of the time it includes complex processes such as thermodynamic activities of vibration relaxation, energy transfer, et al., radiation transitions of fluorescence, delayed fluorescenc, et al., as well as non-radiative transitions of internal conversion, intersystem cross, et al.,hencethe yield of isomerization and reverse isomerization will not be the same.Due to the high energy barrier of the double bond isomerization reaction, it is extremely difficult to realize by thermochemical methods, moreover, the action time is such long, so it is realized by photochemical method.As mentioned above, the vertical excitation energies $(\mathrm{S} 0-\mathrm{S} 1)$ of $(E)-\mathbf{1}$ and $(Z)-\mathbf{1}$ are $3.98 \mathrm{eV}\left(91.78 \mathrm{kcal} \cdot \mathrm{mol}^{-1}\right)$ and $4.26 \mathrm{eV}\left(98.24 \mathrm{kcal} \cdot \mathrm{mol}^{-1}\right)$, respectively.After absorbing the light quantum energy, if the other excited states decay processesare controlled as weak as possible, and then, the photochemical 
isomerization processes of $(E)-\mathbf{1} \rightarrow(Z)-\mathbf{1}$ and $(Z)-\mathbf{1} \rightarrow(E)$-1are relatively easy, which is also in good agreement with the experimental conclusions.

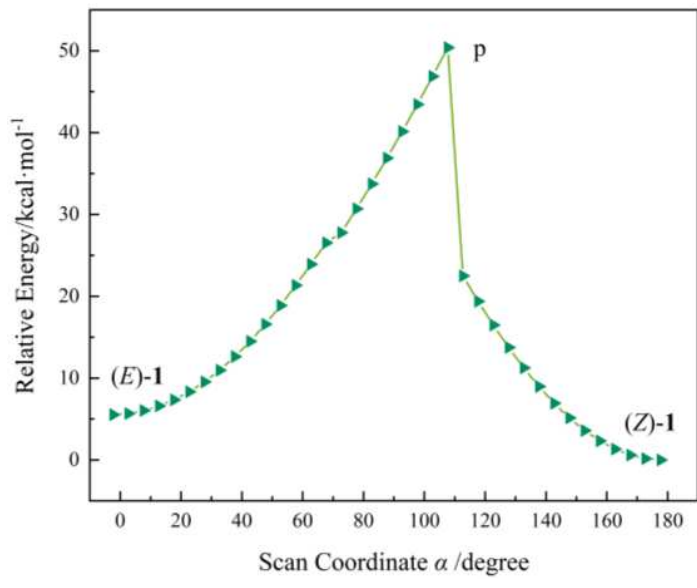

(a)

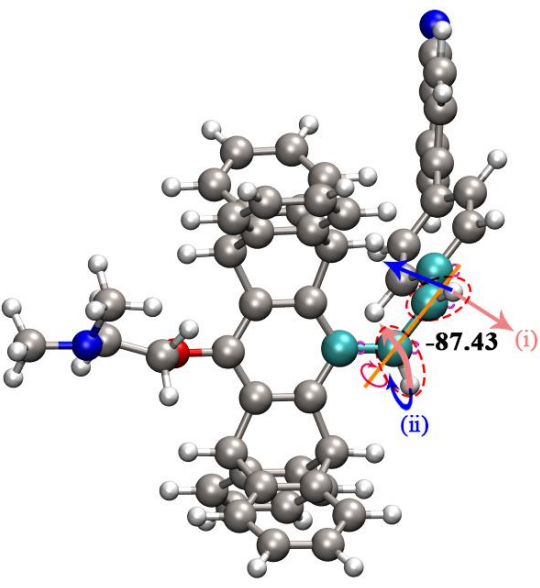

(b)

Figure 10. (a) Minimum energy profile of double bond isomerization, and (b) molecular structure diagram of transition state optimization.

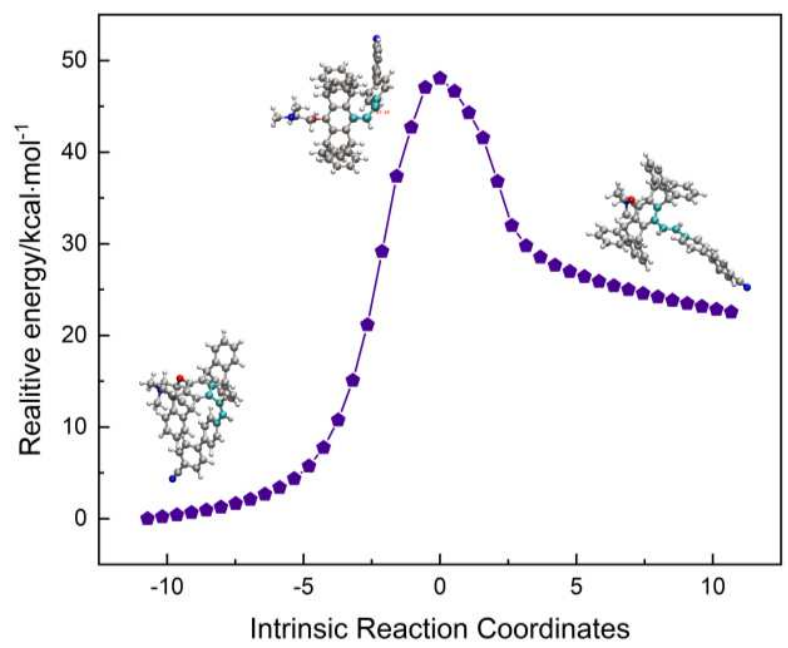

Figure 11. The intrinsic reaction coordinate curve of the transition state of the double bond isomerization and the corresponding molecular structure.

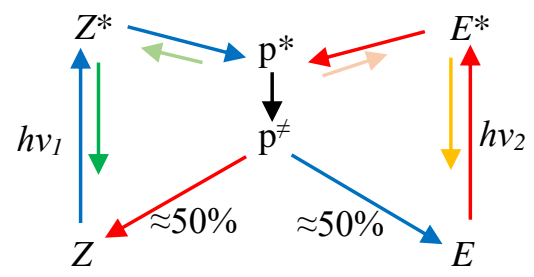

Figure 12. The general reaction mechanism of photoisomerization $\left(Z, E, Z^{*}, E^{*}, \mathrm{p}^{\neq}\right.$, and $\mathrm{p}^{*}$ stand for the (E)-type, (Z)-type, excited state of (E)-type, excited state of (Z)-type, intermediate in ground state, and intermediate in excited state, respectively). 


\section{CONCLUSIONS}

The analyses indicate that when the molecule adopts the $(E)$-type, the energy barrier is small due to the low rotation resistance, and it is in fast rotation.After being irradiated by light, a photoisomerization reaction occurs and it is converted into $(Z$ )-type, which makes the brake padinsert into the pentiptycene paddle, the rotation resistance increases. What's more, the energy barrier rises to the rotation hindered range, and the rotation speed significantly reduce, so as to achieve the purpose of braking.In the process, the electron transition caused by light excitation further leads to the partial transfer of the electron, and this exist in both configurations. The results of NTOs and absorption spectra analyses show that the ratio of $(E)$-configurationhas stronger conjugation and electron delocalization than (Z)-configuration, and the wavelengths of light radiation required for excitationsareshorter. The discussions of the mechanism of the isomerization reveal that the reaction occurs in the $\mathrm{S} 1$ excited state and undergoes an intermediate with a torsion angle of nearly $90^{\circ}$. If the molecule is converted back and forth under different wavelengths of light, it can be like a macro brake to realize the controllable adjustments of rotation motions in molecular level. 


\section{REFRENCES}

1. Kottas, G. S.; Clarke, L. I.; Horinek, D.; Michl, J. Artificial molecular rotors. Chem. Rev.2005, 105(4): 1281-1376.

2. van Leeuwen, T.; Danowski, W.; Pizzolato, S. F.; Štacko, P.; Wezenberg, S. J.; Feringa, B. L. Braking of a light-driven molecular rotary motor by chemical stimuli. Chem. Eur. J.2018, 24(1): 81-84.

3. Roke, D.; Stuckhardt, C.; Danowski, W.; Wezenberg, S. J.; Feringa, B. L. Light-gated rotation in a molecular motor functionalized with a dithienylethene switch. Angew. Chem. Int. Ed. Engl.2018, 57(33): 10515-10519.

4. Kao, C.Y.; Lu, H. F.; Chao, I.; Yang, J.S. A rotary molecular motor gated by electrical energy. Org. Lett.2014, 16(23): 6100-6103.

5. Kelly, T. R.; Bowyer, M. C.; Bhaskar, K. V.; Bebbington, D.; Garcia, A.; Lang, F.; Kim, M. H.; Jette, M. P. A molecular brake. J. Am. Chem. Soc.1994, 116(8): 3657-3658.

6. Kelly, T. R. Progress toward a rationally designed molecular motor. Acc. Chem. Res.2001, 34(6): 514-522.

7. Kelly, T. R.; Sestelo, J. P.; Tellitu, I. New molecular devices: In search of a molecular ratchet. J. Org. Chem.1998, 63(11): 3655-3665.

8. Kelly, T. R.; De Silva, H.; Silva, R. A. Unidirectional rotary motion in a molecular system. Nature1999, 401(6749): $150-152$.

9. Kelly, T. R.; Cai, X.; Damkaci, F.; Panicker, S. B.; Tu, B.; Bushell, S. M.; Cornella, I.; Piggott, M. J.; Salives, R.; Cavero, M.; Zhao, Y.; Jasmin, S. Progress toward a rationally designed, chemically powered rotary molecular motor. J. Am. Chem. Soc.2007, 129(2): 376-386.

10. Wang, G.; Ma, L.; Xiang, J.; Wang, Y.; Chen, X.; Che, Y.; Jiang, H. 2,6-Pyridodicarboxamide-bridged triptycene molecular transmission devices: Converting rotation to rocking vibration. J. Org. Chem.2015, 80(22): 11302-11312.

11. Toyota, S.; Kawahata, K.; Sugahara, K.; Wakamatsu, K.; Iwanaga, T. Triple and quadruple triptycene gears in rigid macrocyclic frameworks. Eur. J. Org. Chem.2017, 2017(37): 5696-5707.

12. Huang, F.; Wang, G.; Ma, L.; Wang, Y.; Chen, X.; Che, Y.; Jiang, H. Molecular spur gears based on a switchable quinquepyridine foldamer acting as a stator. J. Org. Chem.2017, 82(23): 12106-12111.

13. Frantz, D. K.; Linden, A.; Baldridge, K. K.; Siegel, J. S. Molecular spur gears comprising triptycene rotators and bibenzimidazole-based stators. J. Am. Chem. Soc.2012, 134(3): 1528-1535.

14. Nikitin, K.; Müller-Bunz, H.; Ortin, Y.; McGlinchey, M. J. A molecular paddlewheel with a sliding organometallic latch: Syntheses, X-ray crystal structures and dynamic behaviour of $\left[\mathrm{Cr}(\mathrm{CO})_{3}\left\{\eta^{6}-2-(9-\right.\right.$ triptycyl)indene $\left.\}\right]$, and of $\left[\mathrm{M}(\mathrm{CO})_{3}\left\{\eta^{5}-2-(9\right.\right.$-triptycyl)indenyl $\left.\}\right](\mathrm{M}=\mathrm{Mn}, \mathrm{Re})$. Chem. Eur. 
J.2009, 15(8): 1836-1843.

15. Yang, J.S.; Huang, Y.T.; Ho, J.H.; Sun, W.T.; Huang, H.H.; Lin, Y.C.; Huang, S.J.; Huang, S.L.; Lu, H. F.; Chao, I. A pentiptycene-derived light-driven molecular brake. Org. Lett.2008, 10(11): 2279-2282.

16. Sun, W.T.; Huang, Y.T.; Huang, G.J.; Lu, H.F.; Chao, I.; Huang, S.L.; Huang, S.J.; Lin, Y.C.; Ho, J.H.; Yang, J. S. Pentiptycene-derived light-driven molecular brakes: Substituent effects of the brake component. Chem. Eur. J.2010, 16(38): 11594-11604.

17. Sun, W.T.; Huang, G.J.; Huang, S.L.; Lin, Y.C.; Yang, J. S. A light-gated molecular brake with antilock and fluorescence turn-on alarm functions: Application of singlet-state adiabatic cis $\rightarrow$ transphotoisomerization. $J$. Org. Chem.2014, 79(13): 6321-6325.

18. Sun, W.T.; Huang, S.L.; Yao, H.H.; Chen, I. C.; Lin, Y.C.; Yang, J. S. An antilock molecular braking system. Org. Lett.2012, 14(16): 4154-4157.

19. Tan, W. S.; Chuang, P.Y.; Chen, C.H.; Prabhakar, C.; Huang, S.J.; Huang, S.L.; Liu, Y.H.; Lin, Y.C.; Peng, S.M.; Yang, J. S. Light-gated molecular brakes based on pentiptycene-incorporated azobenzenes. Chem. Eur. J.2015, 10(4): 989-997.

20. Yang, C.H.; Prabhakar, C.; Huang, S.L.; Lin, Y.C.; Tan, W. S.; Misra, N. C.; Sun, W.T.; Yang, J. S. A redox-gated slow-fast-stop molecular rotor. Org. Lett.2011, 13(20): 5632-5635.

21. Kao, C.Y.; Lee, I. T.; Prabhakar, C.; Yang, J.S. Light- and redox-gated molecular brakes consisting of a pentiptycene rotor and an indole pad. J. Chin. Chem. Soc.2014, 61(5): 507-516.

22. Tseng, T.; Lu, H.F.; Kao, C.Y.; Chiu, C.W.; Chao, I.; Prabhakar, C.; Yang, J. S. Redox-gated tristable molecular brakes of geared rotation. J. Org. Chem.2017, 82(10): 5354-5366.

23. Basheer, M. C.; Oka, Y.; Mathews, M.; Tamaoki, N. A light-controlled molecular brake with complete on-off rotation. Chem. Eur. J.2010, 16(11): 3489-3496.

24. Iwasaki, Y.; Morisawa, R.; Yokojima, S.; Hasegawa, H.; Roussel, C.; Vanthuyne, N.; Caytan, E.; Kitagawa, O. $\mathrm{N}-\mathrm{C}$ axially chiral anilines: Electronic effect on barrier to rotation and a remote proton brake. Chem. Eur. J.2018, 24(17): 4453-4458.

25. Han, S.; Wu, Y.; Duan, R.; Jiang, H.; Wang, Y. Fluoride-controlled molecular brake systems. Asian J. Org. Chem.2019, 8(1): 83-87.

26. Chen, G.; Zhao, Y. Redox-regulated rotary motion of a bis(9-triptycyl)-TTFVsystem. Org. Lett.2014, 16(3): $668-671$.

27. Nikitin, K.; Bothe, C.; Müller-Bunz, H.; Ortin, Y.; McGlinchey, M. J. High and low rotational barriers in metal tricarbonyl complexes of 2- and 3-indenyl anthracenes and triptycenes: Rational design of molecular 
brakes. Organometallics 2012, 31(17): 6183-6198.

28. Hirose, K. Molecular brake systems controlled by light and heat. J. Incl. Phenom. Macro.2010, 68(1): 1-24.

29. Erbas-Cakmak, S.; Leigh, D. A.; McTernan, C. T.; Nussbaumer, A. L. Artificial molecular machines. Chem. Rev.2015, 115(18): 10081-10206.

30. Chai, J. D.; Head-Gordon, M. Long-range corrected hybrid density functionals with damped atom-atom dispersion corrections. Phys. Chem. Chem. Phys.2008, 10(44): 6615-6620.

31. Dennington, R.; Keith, T.; Millam, J. GaussView 5.0.8. Semichem, Inc.: Shawnee Mission, KS, 2009.

32. Humphrey, W.; Dalke, A.; Schulten, K. VMD: Visual molecular dynamics. J. Mol. Graphics1996, 14(1): $33-38$.

33. Hehre, W. J.; Ditchfield, R.; Pople, J. A. Self-consistent molecular orbital methods. XII. further extensions of gaussian — type basis sets for use in molecular orbital studies of organic molecules. J. Chem. Phys.1972, 56(5): 2257-2261.

34. McLean, A. D.; Chandler, G. S. Contracted gaussian basis sets for molecular calculations. I. second row atoms, Z=11-18. J. Chem. Phys.1980, 72(10): 5639-5648.

35. Schlegel, H. B. Optimization of equilibrium geometries and transition structures. J. Comput. Chem.1982, 3(2): 214-218.

36. Lu, T.; Chen, F. Multiwfn: A multifunctional wavefunction analyzer. J. Comput. Chem.2012, 33(5): 580-592.

37. Lu, T.; Chen, F. Quantitative analysis of molecular surface based on improved marching tetrahedra algorithm. J. Mol. Graph. Model.2012, 38: 314-323.

38. Lu, T.; Chen, F. Comparison of computational methods for atomic charges. Acta Phys. Chim. Sin.2012, 28(1): $1-18$.

39. Frisch, M. J.; Trucks, G. W.; Schlegel, H. B.; Scuseria, G. E.; Robb, M. A.; Cheeseman, J. R.; Scalmani, G.; Barone, V.; Petersson, G. A.; Nakatsuji, H.; Li, X.; Caricato, M.; Marenich, A.; Bloino, J.; Janesko, B. G.; Gomperts, R.; Mennucci, B.; Hratchian, H. P.; Ortiz, J. V.; Izmaylov, A. F.; Sonnenberg, J. L.; Williams-Young, D.; Ding, F.; Lipparini, F.; Egidi, F.; Goings, J.; Peng, B.; Petrone, A.; Henderson, T.; Ranasinghe, D.; Zakrzewski, V. G.; Gao, J.; Rega, N.; Zheng, G.; Liang, W.; Hada, M.; Ehara, M.; Toyota, K.; Fukuda, R.; Hasegawa, J.; Ishida, M.; Nakajima, T.; Honda, Y.; Kitao, O.; Nakai, H.; Vreven, T.; Throssell, K.; Montgomery, J. A.; Peralta, J. E. Jr.; Ogliaro, F.; Bearpark, M.; Heyd, J. J.; Brothers, E.; Kudin, K. N.; Staroverov, V. N.; Keith, T.; Kobayashi, R.; Normand, J.; Raghavachari, K.; Rendell, A.; Burant, J. C.; Iyengar, S. S.; Tomasi, J.; Cossi, M.; Millam, J. M.; Klene, M.; Adamo, C.; Cammi, R.; Ochterski, J. W.; Martin, R. L.; Morokuma, K.; Farkas, O.; Foresman, J. B.; Fox, D. J.Gaussian 09, Revision D.01; Gaussian, 
Inc.: Wallingford, CT, 2013.

40. Schäfer, A.; Huber, C.; Ahlrichs, R. Fully optimized contracted gaussian basis sets of triple zeta valence quality for atoms Li to Kr. J. Chem. Phys.1994, 100(8): 5829-5835.

41. Eliel, E. L.; Wilen, S. H.; Doyle, M. P. Basic organic stereochemistry. John Wiley \& Sons Inc.,New York,2001, 30-44

42. Wade, L. G., Jr. Organic chemistry. 5th edition, Pearson Education Inc., Upper Saddle River, 2003, 80-121.

43. Solomons, T. W. G.; Fryhle, C. B. Organic chemistry. 8th edition, John Wiley \& Sons Inc.,New York,2004, 134-186.

44. Alecu, I. M.; Zheng, J.; Zhao, Y.; Truhlar, D. G. Computational thermochemistry: Scale factor databases and scale factors for vibrational frequencies obtained from electronic model chemistries. J. Chem. Theory Comput.2010, 6(9): 2872-2887.

45. Irikura, K. K.; Johnson, R. D.; Kacker, R. N.; Kessel, R. Uncertainties in scaling factors for ab initio vibrational zero-point energies. J. Chem. Phys.2009, 130(11): 114102.

46. Johnson, R. D. IINIST computational chemistry comparison and benchmark database: NIST standard reference database number 101, release 21 (August 2020), avaliable at: http://cccbdb.nist.gov/.

47. Zhao, Y.; Truhlar, D. G. The M06 suite of density functionals for main group thermochemistry, thermochemical kinetics, noncovalent interactions, excited states, and transition elements: two new functionals and systematic testing of four M06-class functionals and 12 other functionals. Theor. Chem. Acc.2008, 120(1): 215-241

48. Boese, A. D.; Martin, J. M. L. Development of density functionals for thermochemical kinetics. J. Chem. Phys.2004, 121(8): 3405-3416.

49. Yanai, T.; Tew, D. P.; Handy, N. C. A new hybrid exchange-correlation functional using thecoulomb-attenuating method (CAM-B3LYP). Chem. Phys. Lett.2004, 393(1): 51-57.

50. Chen, Y.C.; Sun, W.T.; Lu, H.F.; Chao, I.; Huang, G.J.; Lin, Y.C.; Huang, S.L.; Huang, H.H.; Lin, Y.D.; Yang, J. S. A pentiptycene-derived molecular brake: Photochemical $E \rightarrow Z$ and electrochemical $Z \rightarrow E$ switching of an enone module. Chem. Eur. J.2011, 17(4): 1193-1200. 


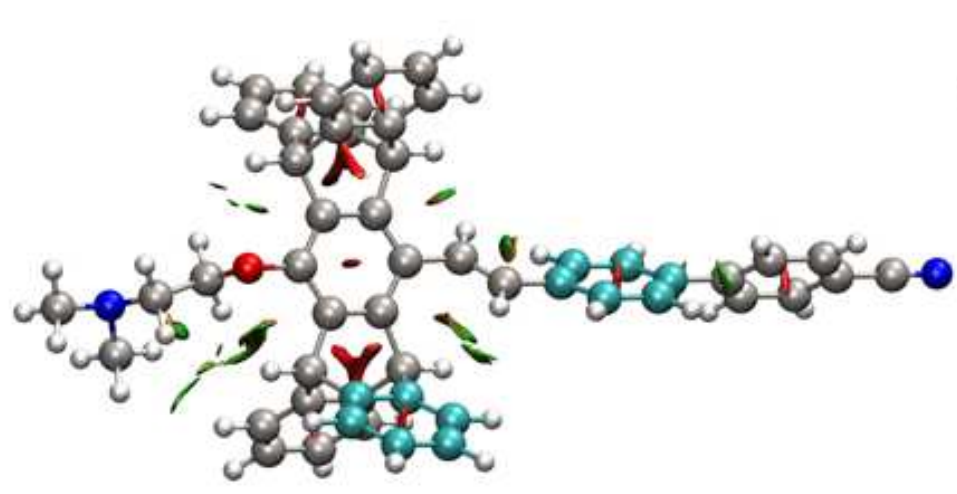

(a) $(E)-1$

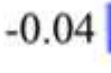

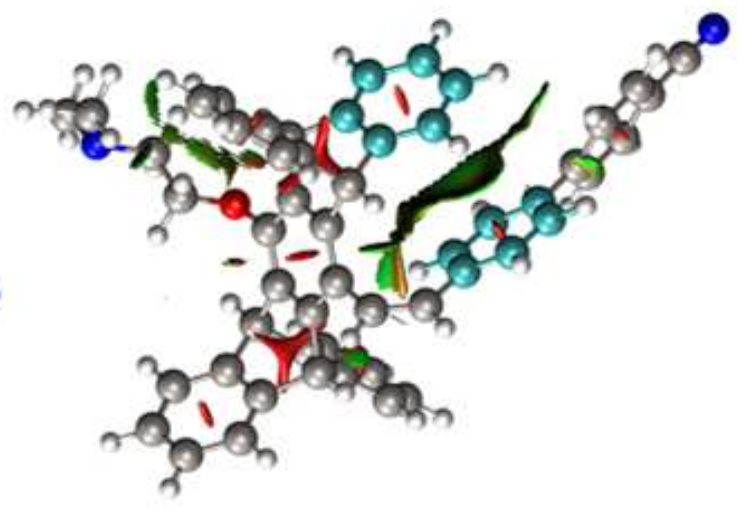

(b) $(Z)-1$

$\begin{array}{ccc}\begin{array}{c}\text { Strong } \\ \text { attraction }\end{array} & \begin{array}{c}\text { Van der Waals } \\ \text { interaction }\end{array} & \begin{array}{c}\text { Strong } \\ \text { repulsion }\end{array}\end{array}$

\section{Figure 1}

The reduced density gradient (RDG) isosurface map of (a) (E)- and (b) (Z)-configuration of molecule 1 . The white are $\mathrm{H}$, the silver are $\mathrm{C}$, the red are $\mathrm{O}$, the blue are $\mathrm{N}$, the cyan are highlighted $\mathrm{C}$.

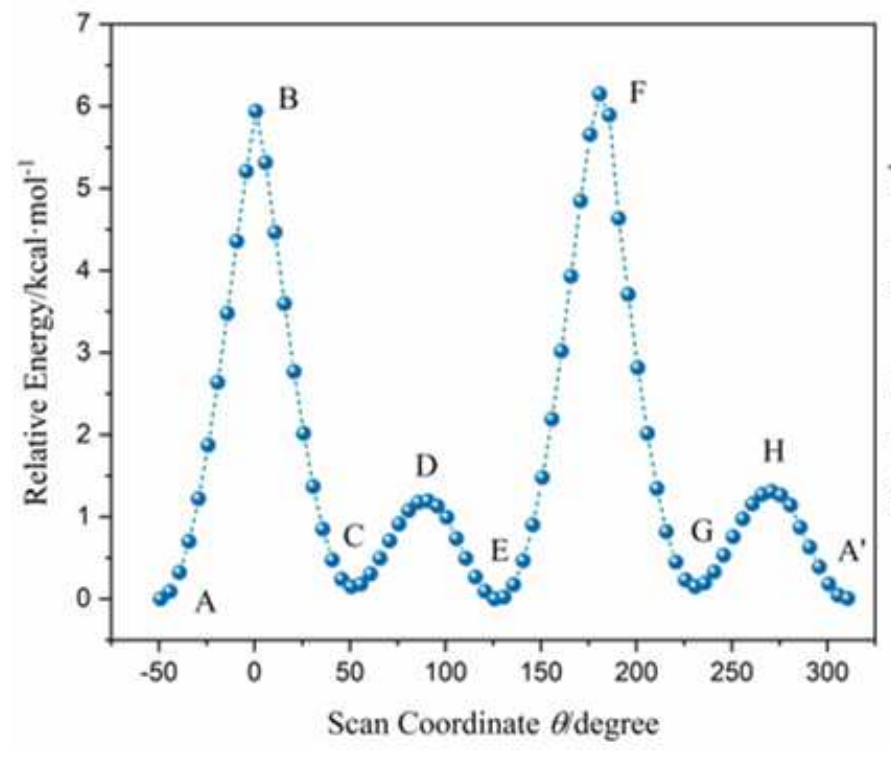

(a)

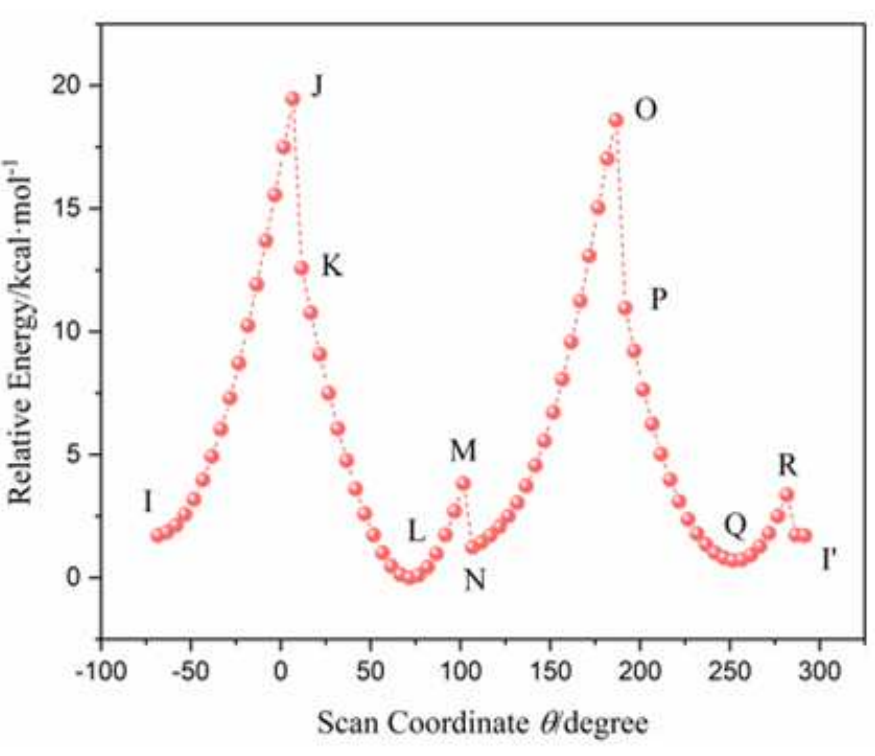

(b)

Figure 2

(a) Minimum energy profile of configuration (E)-1 regarding dihedral angle $\theta$, and (b) minimum energy profile of configuration (Z)-1 regarding dihedral angle $\theta$. 

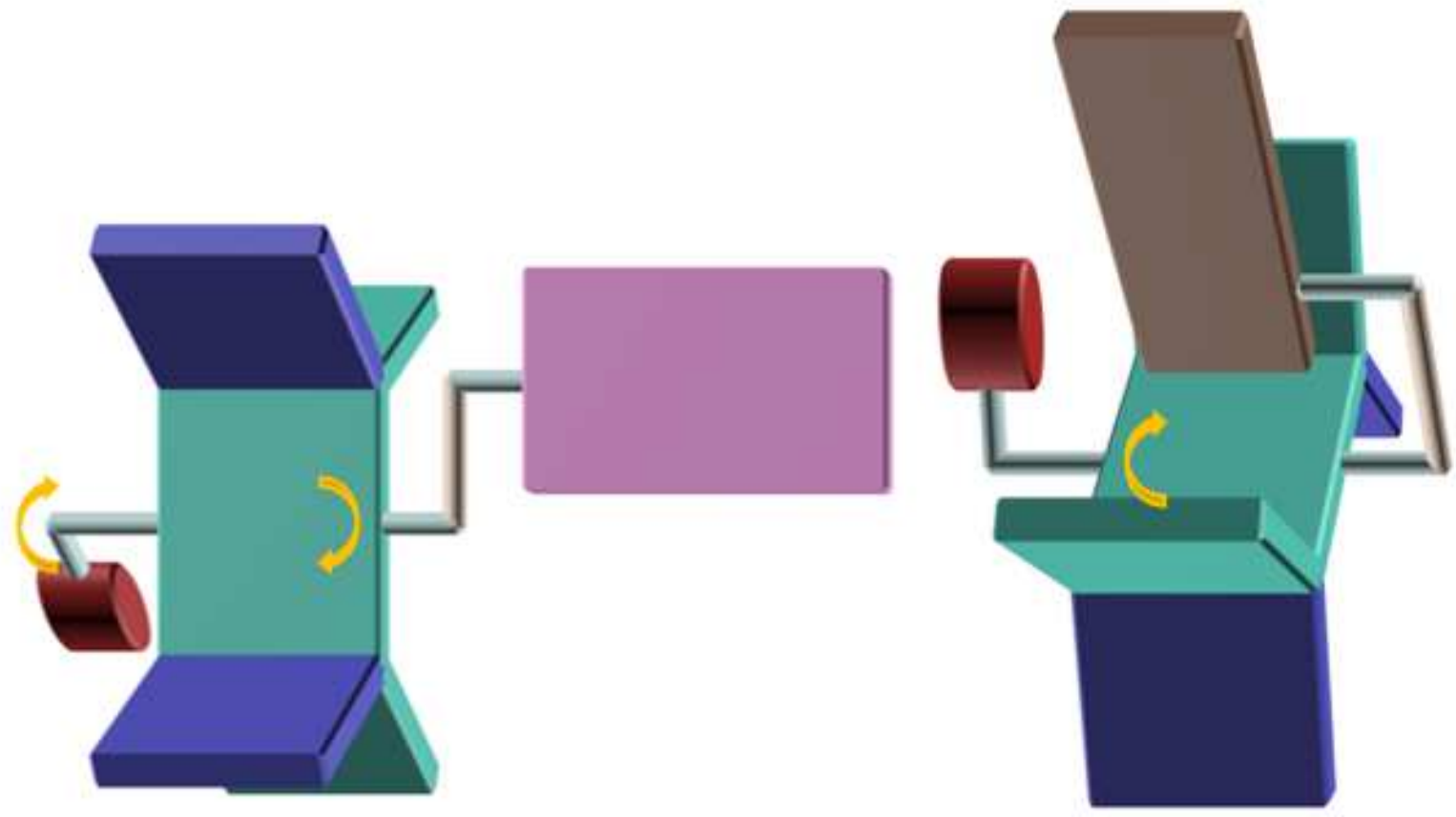

(a)

Figure 3

(a) Macro model diagram of (E)-1, and (b) macro model diagram of (Z)-1.

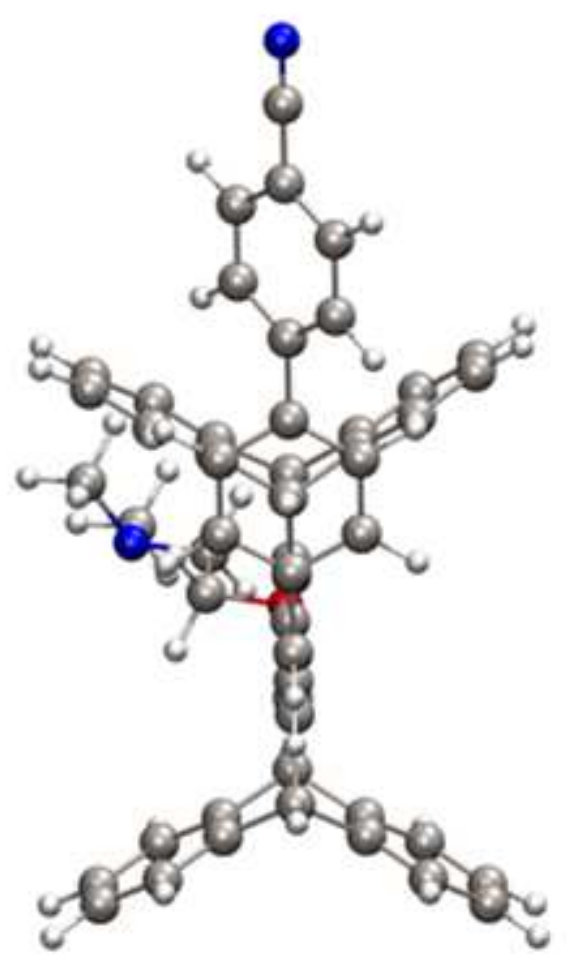

(a) TS1

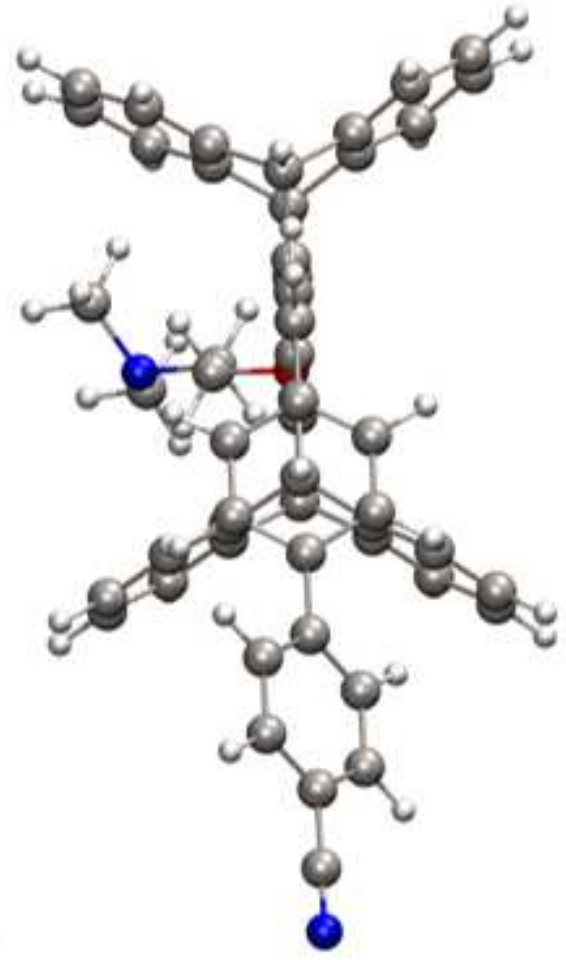

(b) TS2

Figure 4 
The molecular structure of the two rotating transition states: (a) TS1 and (b) TS2 of (Z)-1.
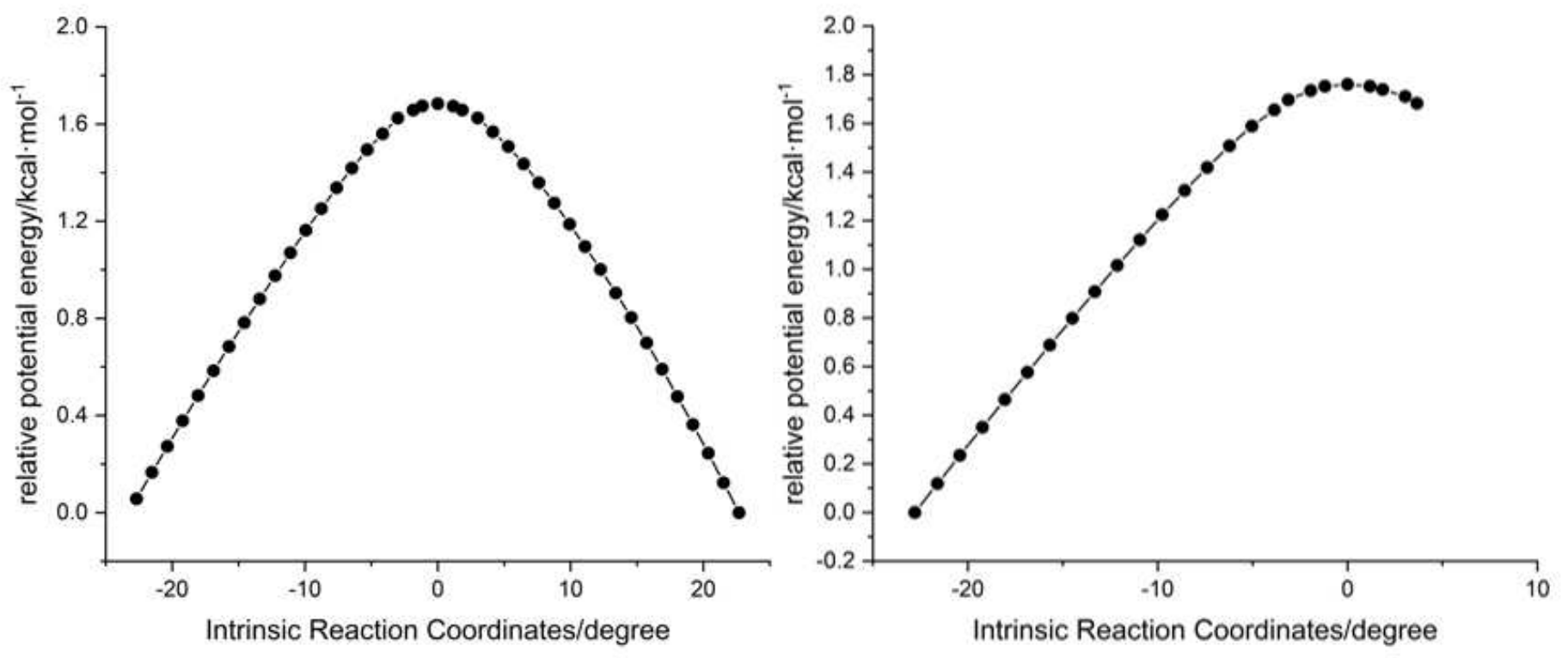

Figure 5

The intrinsic reaction coordinates (IRC) curves for (a) TS1, and (b) TS2 of (E)-1 during rotation.

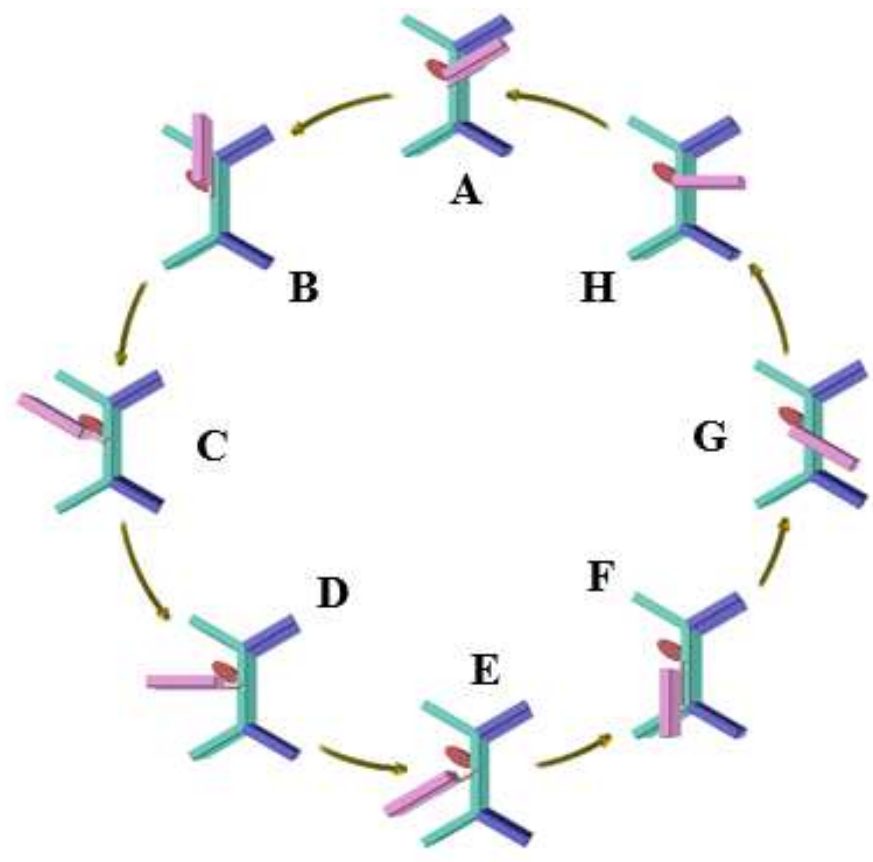

(a) $(E)-1$

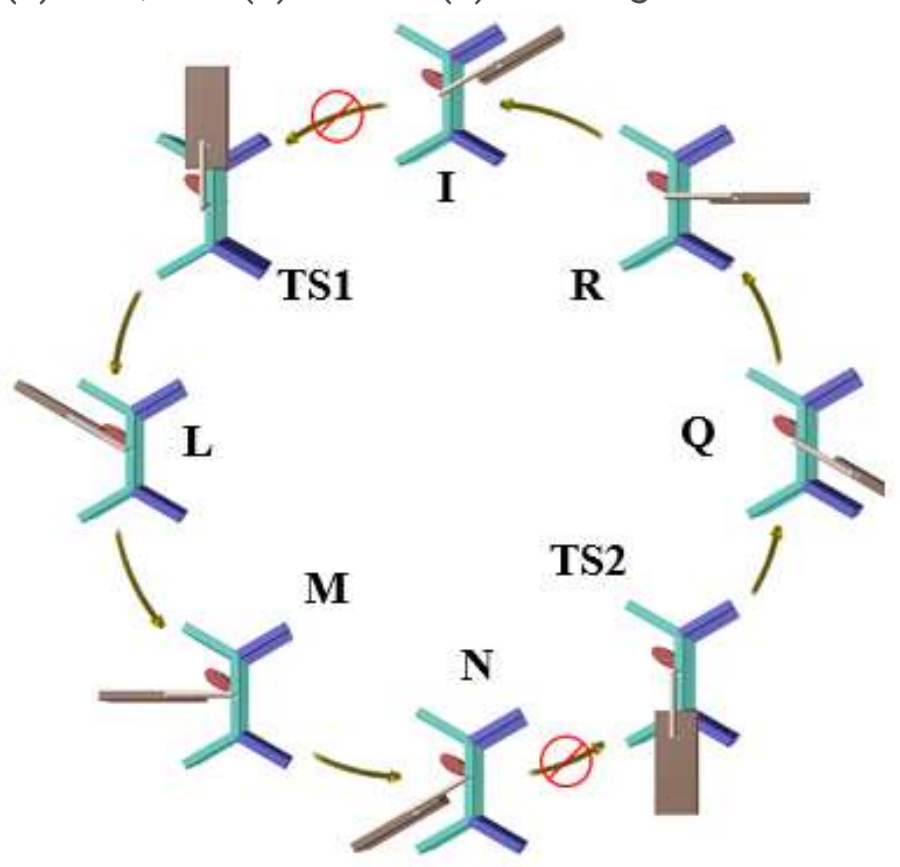

(b) $(Z)-1$

Figure 6

(a) $360^{\circ}$ rotation mechanism diagram of (E)-1, and (b) $360^{\circ}$ rotation mechanism diagram of (Z)- 1 . 

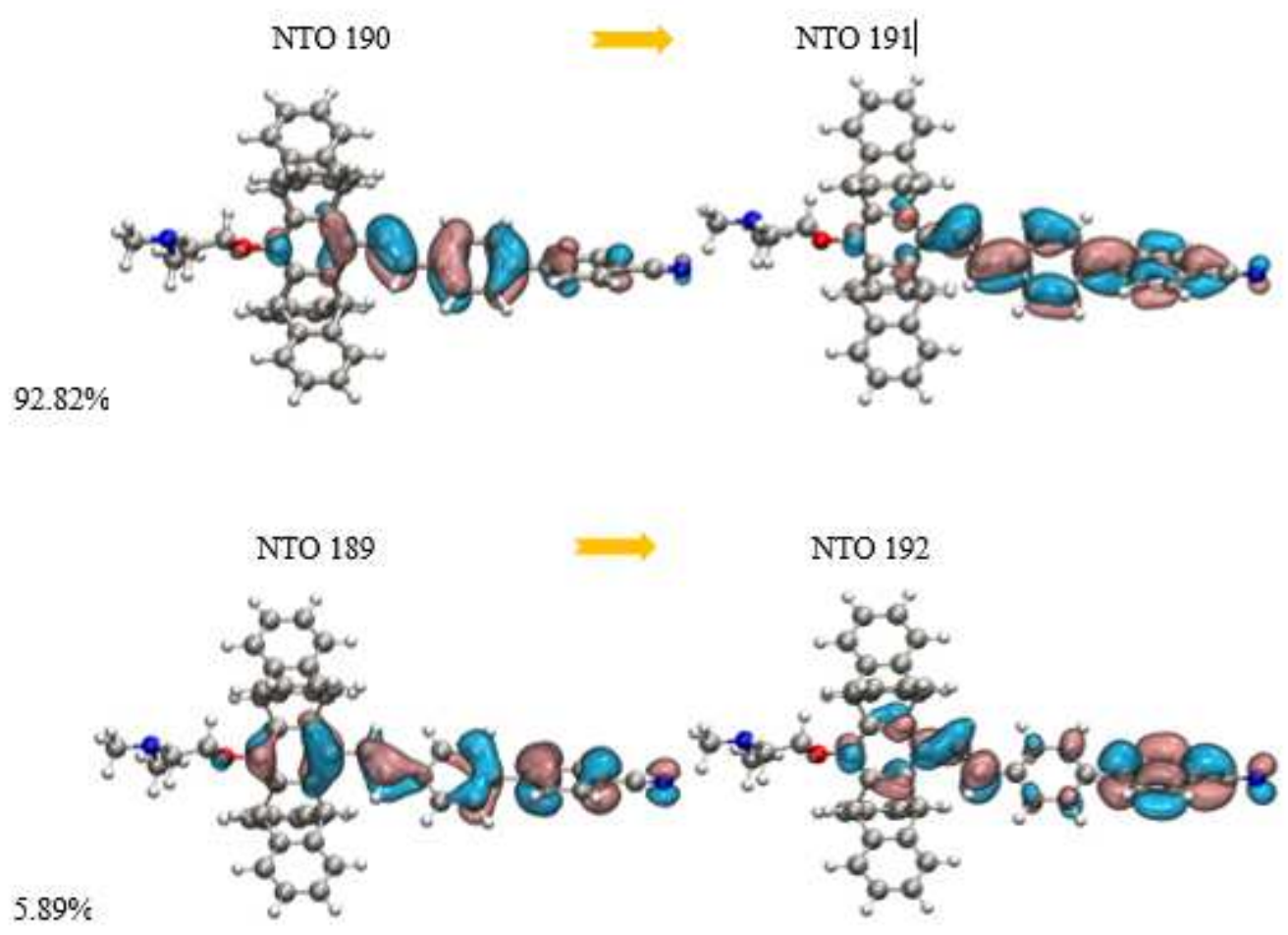

(a) NTO diagrams of $(E)-1$
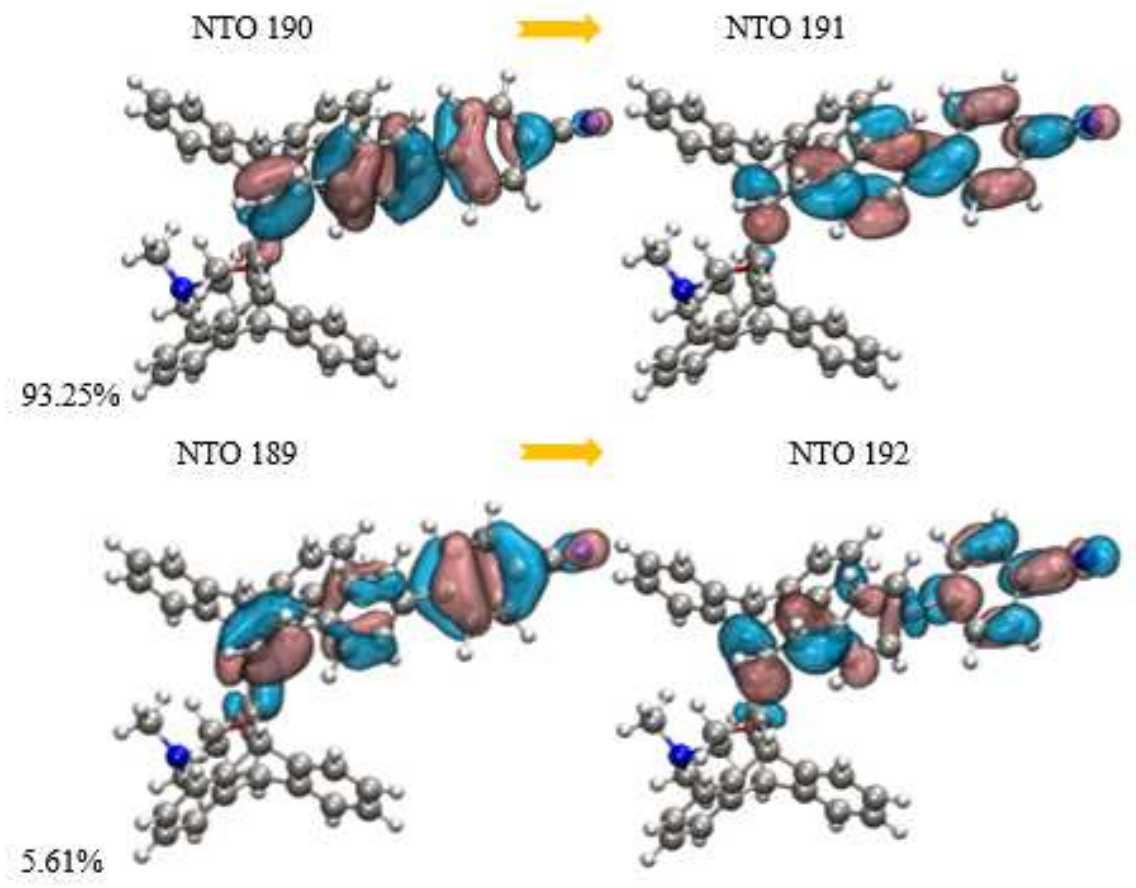

(b) NTO diagrams of (Z)-1

\section{Figure 7}

The dominant and sub-dominant natural transition orbital models of (a) (E)-1, and (b) (Z)-1. 


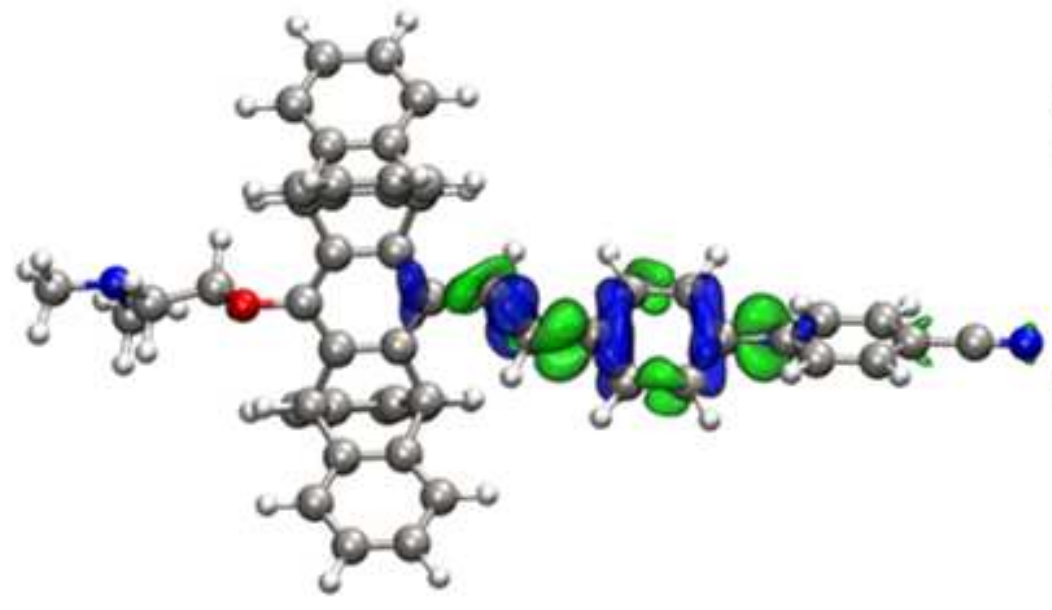

(a)

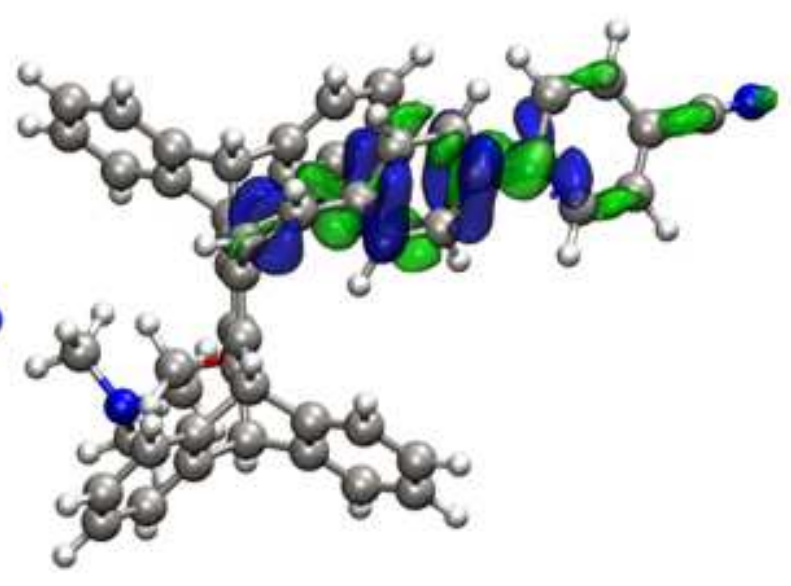

(b)

\section{Figure 8}

The charge density difference (CDD) between the computed excited state (S1) and the ground state of (a) (E)-1, and (b) (Z)-1. The green is where the electron density increases, while the blue is where the electron density decreases.

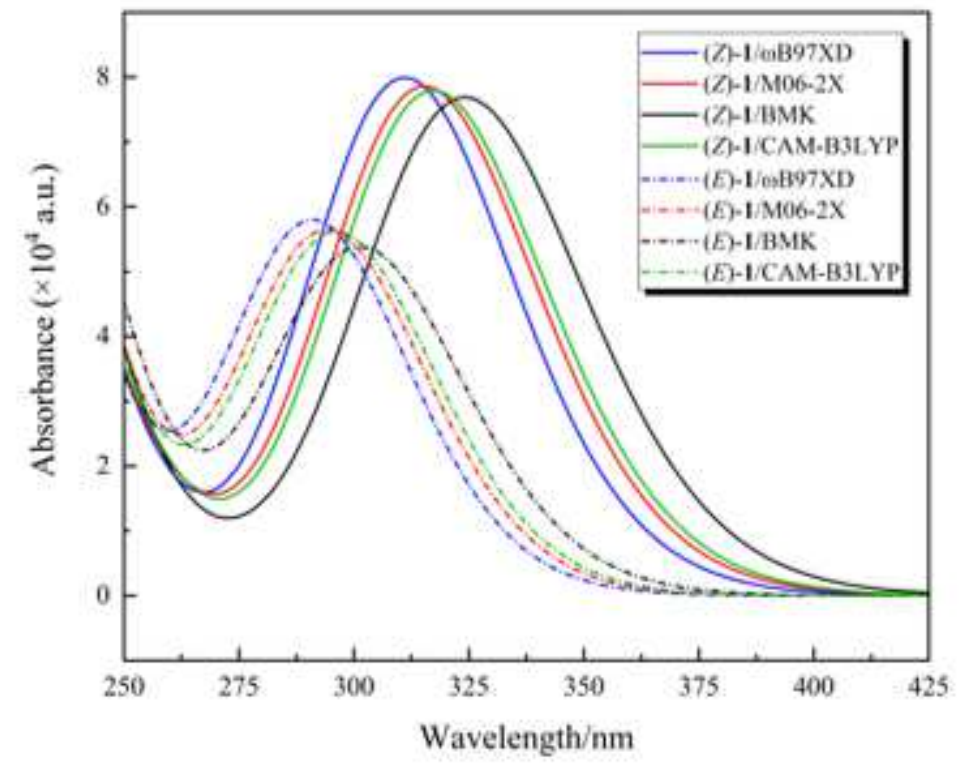

Figure 9

The absorption spectra of (E)-1 and (Z)-1 simulated by different functionals in solvent of acetonitrile. 


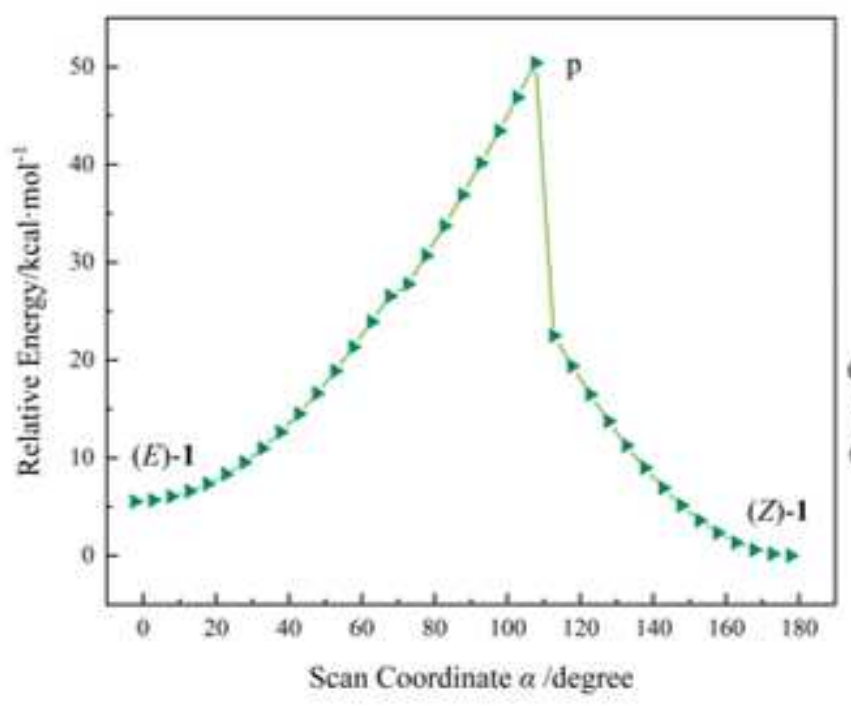

(a)

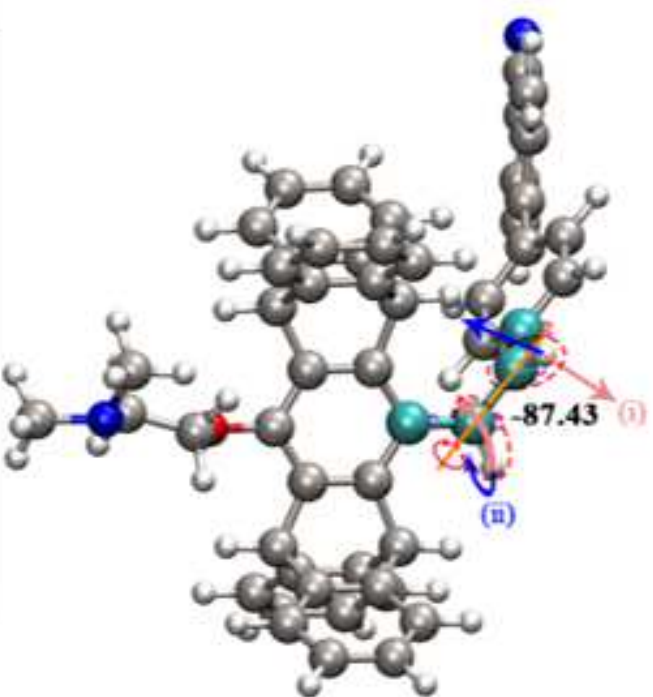

(b)

\section{Figure 10}

(a) Minimum energy profile of double bond isomerization, and (b) molecular structure diagram of transition state optimization.

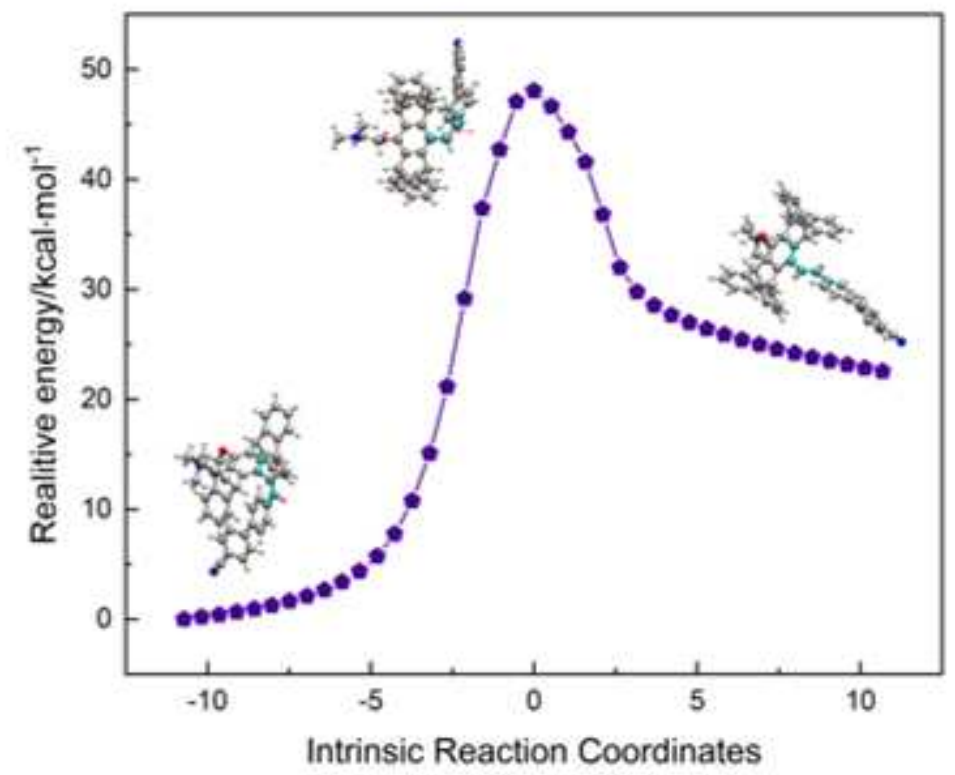

\section{Figure 11}

The intrinsic reaction coordinate curve of the transition state of the double bond isomerization and the corresponding molecular structure. 


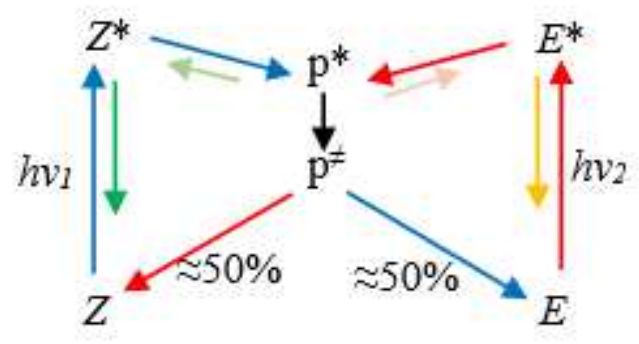

\section{Figure 12}

The general reaction mechanism of photoisomerization $\left(Z, E, Z^{*}, E^{*}, p \neq\right.$, and $p^{*}$ stand for the (E)-type, (Z)type, excited state of (E)-type, excited state of (Z)-type, intermediate in ground state, and intermediate in excited state, respectively).

\section{Supplementary Files}

This is a list of supplementary files associated with this preprint. Click to download.

- HailongWang2GraphicalAbstract.docx 